\title{
1-Methylcyclopropene Modulates Physiological, Biochemical, and Antioxidant Responses of Rice to Different Salt Stress Levels
}

\section{Sajid Hussain, Zhigang Bai, Jie Huang, Xiaochuang Cao, Lianfeng Zhu, Chunquan Zhu, Maqsood Ahmed Khaskheli, Chu Zhong, Qianyu Jin* and Junhua Zhang*}

State Key Laboratory of Rice Biology, China National Rice Research Institute, Hangzhou, China

OPEN ACCESS

Edited by:

Rosa M. Rivero,

Centro de Edafología y Biología Aplicada del Segura (CEBAS), Spain

Reviewed by:

Liang Chen,

University of Chinese Academy of Sciences (UCAS), China

Umair Riaz,

University of Agriculture, Faisalabad,

Pakistan

Asif Ameen,

Gomal University, Pakistan

${ }^{*}$ Correspondence:

Qianyu Jin

jinqianyu@caas.cn

Junhua Zhang

zhangjunhua@caas.cn

Specialty section:

This article was submitted to

Plant Abiotic Stress,

a section of the journal

Frontiers in Plant Science

Received: 07 July 2018 Accepted: 24 January 2019 Published: 21 February 2019

Citation:

Hussain S, Bai Z, Huang J, Cao X,

Zhu L, Zhu C, Khaskheli MA, Zhong C, Jin Q and Zhang J (2019)

1-Methylcyclopropene Modulates

Physiological, Biochemical, and Antioxidant Responses of Rice

to Different Salt Stress Levels.

Front. Plant Sci. 10:124.

doi: 10.3389/fpls.2019.00124
Salt stress in soil is a critical constraint that affects the production of rice. Salt stress hinders plant growth through osmotic stress, ionic stress, and a hormonal imbalance (especially ethylene), therefore, thoughtful efforts are needed to devise salt tolerance management strategies. 1-Methylcyclopropene (1-MCP) is an ethylene action inhibitor, which could significantly reduce ethylene production in crops and fruits. However, 1MCPs response to the physiological, biochemical and antioxidant features of rice under salt stress, are not clear. The present study analyzed whether 1-MCP could modulate salt tolerance for different rice cultivars. Pot culture experiments were conducted in a greenhouse in 2016-2017. Two rice cultivars, Nipponbare (NPBA) and Liangyoupeijiu (LYP9) were used in this trial. The salt stress included four salt levels, $0 \mathrm{~g} \mathrm{NaCl} / \mathrm{kg}$ dry soil (control, CK), $1.5 \mathrm{~g} \mathrm{NaCl} / \mathrm{kg}$ dry soil (Low Salt stress, LS), $4.5 \mathrm{~g} \mathrm{NaCl} / \mathrm{kg}$ dry soil (Medium Salt stress, MS), and $7.5 \mathrm{~g} \mathrm{NaCl} / \mathrm{kg}$ dry soil (Heavy Salt stress, HS). Two 1MCP levels, $0 \mathrm{~g}(\mathrm{CT})$ and $0.04 \mathrm{~g} / \mathrm{pot}(1-\mathrm{MCP})$ were applied the rice booting stage in 2016 and 2017. The results showed that applying 1-MCP significantly reduced ethylene production in rice spikelets from LYP9 and NPBA by 40.2 and $23.9 \%$ (CK), 44.3 and 28.6\% (LS), 28 and 25.9\% (MS), respectively. Rice seedlings for NPBA died under the HS level, while application of 1-MCP reduced the ethylene production in spikelets for LYP9 by $27.4 \%$ compared with those that received no 1-MCP treatment. Applying 1MCP improved the photosynthesis rate and SPAD value in rice leaves for both cultivars. 1-MCP enhanced the superoxide dismutase production, protein synthesis, chlorophyll contents (chl $a, b$, carotenoids), and decreased malondialdehyde, $\mathrm{H}_{2} \mathrm{O}_{2}$, and proline accumulation in rice leaves. Application of 1-MCP also modulated the aboveground biomass, and grain yield for LYP9 and NPBA by 19.4 and 15.1\% (CK), 30.3 and 24\% (LS), 26.4 and 55.4\% (MS), respectively, and 34.5\% (HS) for LYP9 compared with those that received no 1-MCP treatment. However, LYP9 displayed a better tolerance than NPBA. The results revealed that 1-MCP could be employed to modulate physiology, biochemical, and antioxidant activities in rice plants, at different levels of salt stress, as a salt stress remedy.

Keywords: rice cultivar, 1-methylcyclopropene, ethylene, sodium chloride, antioxidants, photosynthesis 


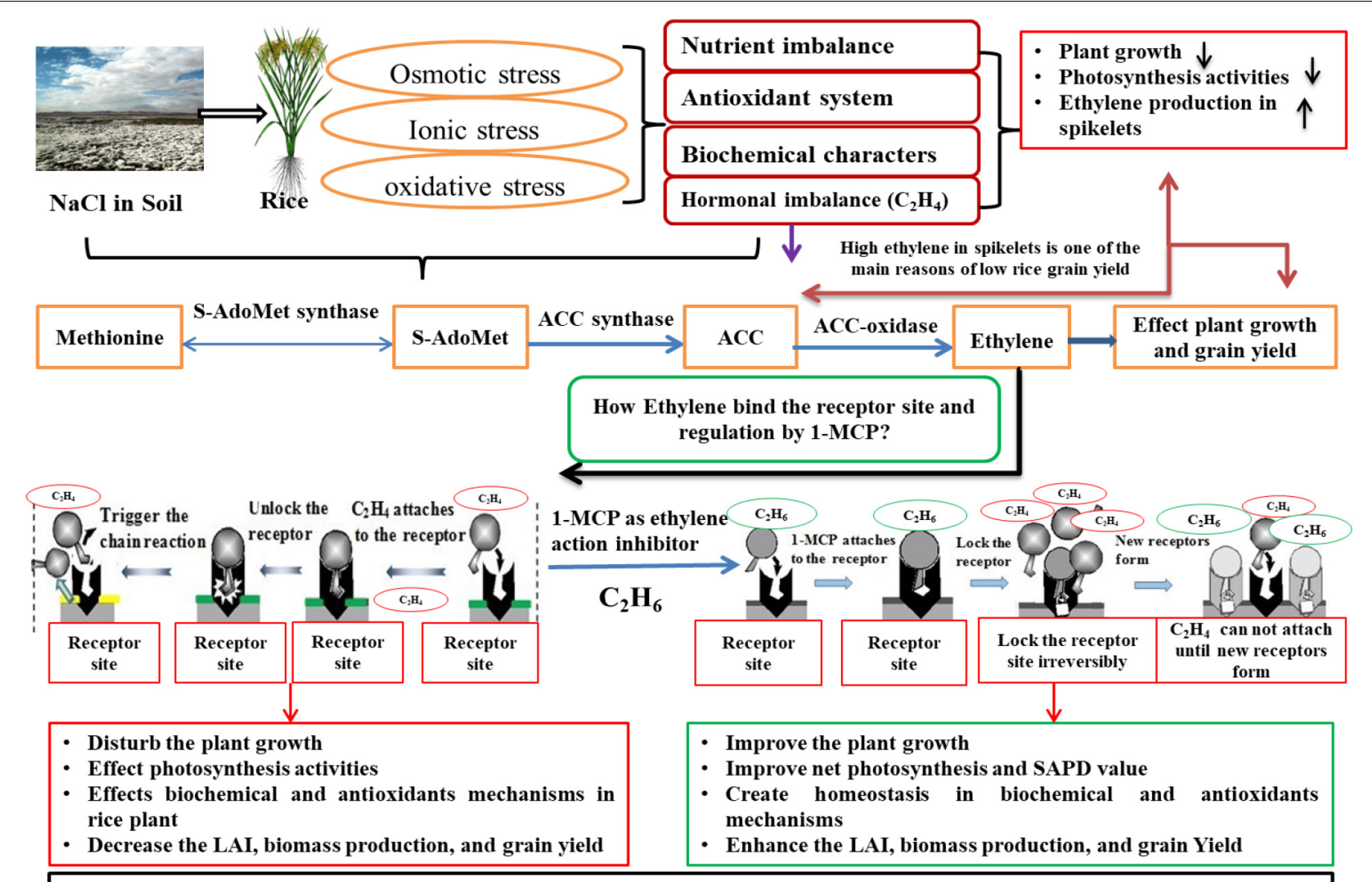

Graphical abstract: 1-Methylcyclopropene modulates physiological, biochemical, and antioxidant responses of rice to different salt stress levels

GRAPHICAL ABSTRACT | 1-Methylcyclopropene modulates physiological, biochemical, and antioxidant responses to different salt stress levels in rice.

\section{INTRODUCTION}

Due to a high and increasing annual population rate, crop production needs to be increased by $87 \%$ by 2050 (Kromdijk and Long, 2016). However, abiotic stresses such as salinity, high temperatures and drought are main factors that reduce crop growth and yield, in large areas of the world (Pareek et al., 2010; Mantri et al., 2012). Globally, abiotic stress, such as salinity is a crucial hurdle preventing the increase of crop production in growing areas (Munns, 2011; Zhang et al., 2017). Globally, approximately $20 \%$ of irrigated agricultural land is under salt stress, as reported by the United Nations Environment Program (UNEP) (Nellemann et al., 2009; Ruan et al., 2010). The area of salt-affected soil is increasing due to global warming, high temperatures and rising sea levels (Rabbani et al., 2013; Islam et al., 2015a). Excessive salt stress can induce several adverse effects in plants, such as osmotic, ionic, and oxidative stress, hormonal imbalances (ethylene production in crops), through the accumulation of $\mathrm{Na}^{+}$and $\mathrm{Cl}^{-}$in plant tissues, and the overproduction of reactive oxygen species (ROS) (Miller et al., 2010; Sajid et al., 2018).

Rice is a salt-sensitive crop (Roy et al., 2014; Parihar et al., 2015). Areas affected by salinity are expanding, becoming a critical global issue that obstructs the sustainability of rice production (Hairmansis et al., 2017). Osmotic stress, due to saltinduced stomatal closure, increases leaf temperature and inhibits shoot growth (Rajendran et al., 2009; Roy et al., 2014). Therefore, through osmotic stress, salt stress inhibits plant growth and directs the senescence of older leaves in plants (Islam et al., 2017a,b). Generally, salt stress has numerous inhibitory effects on rice plants, including reduced leaf emergence, shoot cell enlargement, photosynthesis rates, chlorophyll contents, and water use efficiency (Amirjani, 2010). Salt stress also significantly influences the leaf area index and dry matter production in rice plants (Amirjani, 2010; Sajid et al., 2018). Salt stress disturbs the balance between the scavenging and production of ROS in plants. This disequilibrium can cause significant damage to cell structures through a sharp escalation of ROS in intracellular tissues (Sharma et al., 2012).

Reactive oxygen species are located in various cellular components such as mitochondria, peroxisomes, and chloroplasts (Del Rio et al., 2006; Navrot et al., 2007). As a result, they can harm the chloroplast pigments, proteins, membrane lipids, enzymes, and nucleic acids (Del Rio et al., 2006). The balance between the production and scavenging of ROS is critical for the survival of plants in unfavorable 
environments. The glyoxalase systems and antioxidant defense system is intermixed. Therefore, the proficiency of these systems needs to be interrelated to improve tolerance levels of abiotic stressors in numerous crops (Mustafiz et al., 2011).

Numerous plant types can protect themselves from osmotic and ionic stress through biosynthesizing friendly solutes, such as trehalose and proline, stabilizing membranes, and by sustaining water relations, enzymes, and complexes of proteins (Iqbal et al., 2015; Reddy et al., 2015). Protection mechanisms against salt stress persuaded-ROS in plants, are convincingly linked with the conservation of cellular redox equilibrium, which is mostly comprised of a list of antioxidants with an enzymatic nature, such as catalase (CAT), malondialdehyde (MDA), superoxide dismutase (SOD), glutathione S-transferase (GST), and glutathione peroxidase (GPX), along with antioxidants with a non-enzymatic nature, such as ascorbic acid (AsA) and glutathione (GSH) (Shao et al., 2007; Miller et al., 2010).

Ethylene is a key signaling hormone, but its role in rice plants that are under salt stress, is quite complex (Tao et al., 2015). A high accumulation of $\mathrm{Na}^{+}$in rice plants that are under salt stress, increases ethylene production and various enzymatic activities in rice (Zhao and Schaller, 2004). High ethylene release also increases the sensitivity to salt stress (Yang et al., 2014), which leads to plant death. Some studies reported that overexpression of ACSs increased sensitivity to salt and increased ethylene production in plants (Li et al., 2014; Tao et al., 2015). The enzymatic mechanisms interrelated to the assembly of starch in rice grains, were also affected by high ethylene production at the rice grain filling stage, which then reduced the rice grain yield (Zhu et al., 2011; Zhang et al., 2014). In genetic manipulation, the inhibition of ethylene production, through chemical means, is also an alternative approach. The use of ethylene action inhibitors, such as ethephon, 1-methylcyclopropene (1-MCP), and amino-ethoxy vinyl glycine (AVG) are valuable for crops to retain plant yields (Zhang et al., 2009).

Among the ethylene action inhibitors, 1-MCP is an efficient chemical means, which has shown an inhibition to the ethyleneinducible effects on various plant species (Yang et al., 2007). 1MCP is small and has a low molecular weight, and $\alpha$-cyclodextrin $(\alpha-C D)$ complex can capture gaseous 1-MCP, which confirms that it is an environmentally friendly chemical (Trotta et al., 2011). 1-MCP binds ethylene receptor sites irreversibly; therefore, subsequent signal translocation and transformation reactions, related to ethylene, are not provoked (Blankenship and Dole, 2003). It was also reported that binding ethylene receptors with 1-MCP reduced protein synthesis and enzymes which were activated by ethylene production under stress ( $\mathrm{Su}$ and Finlayson, 2012). Modern research has shown that the 1-MCP application improved dry matter segregation, the photosynthesis rate, and chlorophyll content, and also promoted carbon assimilation in rice plants (Wang et al., 2012; Zhang et al., 2014, 2015).

This study was conducted, keeping all the information mentioned above in mind, to prove the hypothesis that higher ethylene production in rice plants, especially in spikelets, is one of the main reasons for lower rice physiological development and grain yield under salt stress conditions. The physiological, biochemical, and antioxidant response to salt stress of different rice cultivars, and the regulation of $1-\mathrm{MCP}$ have not been studied before.

The primary objective of this study was to evaluate the responses of 1-MCP on physiological, biochemical, and antioxidant characteristics in rice under salt stress. The list of physiological traits in rice included net photosynthesis rate $\left(\mathrm{P}_{\mathrm{n}}\right)$ and chlorophyll contents (SPAD values) at the rice full heading stage. The antioxidants attribute involved quantifying SOD, MDA, $\mathrm{H}_{2} \mathrm{O}_{2}$, biochemical features, i.e., Chlorophyll contents (chlorophyll a, b, carotenoids, and total chlorophyll), proline, and the soluble protein concentration in rice flag leaves. Along with the parameters mentioned above, the aboveground biomass and grain yield for rice plants were also measured at maturity. These results will be useful for evaluating the relative abilities of rice cultivars being cultivated in the region and will establish the potential commercial use of 1-MCP against salt stress.

\section{MATERIALS AND METHODS}

\section{Growth Conditions and Experiment Design}

The pot culture experiments were conducted in the greenhouse of the China National Rice Research Institute $\left(31^{\circ} 4^{\prime} 49^{\prime \prime} \mathrm{N}\right.$, $119^{\circ} 56^{\prime} 11^{\prime \prime}$ E), Zhejiang Province, China, in 2016 and 2017. Two rice cultivars, Nipponbare (NPBA, Japonica) and Liangyoupeijiu (LYP9, Indica) were used in this trial. The soil texture used in this experiment was loam clay. Soil (30 kg per pot) was air-dried, ground, and sieved, and filled into pots $(45 \times 30 \mathrm{~cm})$. Six rice seedlings (30-days old) were then transplanted into each pot.

A chemical reagent, sodium chloride $(\mathrm{NaCl})$, was used as a salt stress agent in the soil. Four levels of $\mathrm{NaCl}$ were used, including $0 \mathrm{~g} \mathrm{NaCl} / \mathrm{kg}$ dry soil (control, CK), $1.5 \mathrm{~g} \mathrm{NaCl} / \mathrm{kg}$ dry soil (Low Salt stress, LS), $4.5 \mathrm{~g} \mathrm{NaCl} / \mathrm{kg}$ dry soil (Medium Salt stress, MS), and $7.5 \mathrm{~g} \mathrm{NaCl} / \mathrm{kg}$ dry soil (Heavy Salt stress, HS), respectively. The salt was homogenized with air dried soil before the seedlings were transplanted. The electrical conductivity (EC) values for CK in 2016 and 2017 were $0.0864 \mathrm{dS} \mathrm{m}^{-1}$ and $0.154 \mathrm{dS} \mathrm{m}^{-1}$, for LS were $1.089 \mathrm{dS} \mathrm{m}^{-1}$ and $1.16 \mathrm{dS} \mathrm{m}^{-1}$, for MS were $3.2 \mathrm{dS} \mathrm{m}^{-1}$ and $3.27 \mathrm{dS} \mathrm{m}^{-1}$, and for HS were $4.64 \mathrm{dS} \mathrm{m}^{-1}$ and $4.71 \mathrm{dS} \mathrm{m}^{-1}$, respectively. All pots were divided into two parts, 1-MCP was applied in half of the pots, while the other half was used as the control. The 1-MCP was applied at the rice mid-booting phase with an amount of 0.04 g per pot during 2016 and 2017. Each treatment was replicated three times. The time frame of the crop lifecycle, from sowing to maturity, is given in Table $\mathbf{1}$.

Nipponbare could not survive at the HS level, and all plants died within 15 days of exposure to salt stress after transplanting. Thus, the NPBA results only included three salt stress levels (CK, LS, and MS), and the LYP9 results included all salt stress levels (CK, LS, MS, and HS). In 2017, similar responses were observed in NPBA and LYP9 at HS level. The results for LYP9 and NPBA in 2017 only included the three salt stress levels.

The experimental soil consisted of loamy clay with a $1.12 \mathrm{~g}$ $\mathrm{cm}^{-3}$ bulk density, containing $4.7 \%$ organic matter with $\mathrm{pH}$ 5.95 , and the represented EC was $0.12 \mathrm{dS} \mathrm{m}^{-1}$. Nitrogen was applied in the form of urea ( $\mathrm{N} 46 \%)$, phosphorous was used 
TABLE 1 | Crop data in 2016 and 2017.

\begin{tabular}{|c|c|c|c|c|c|c|c|}
\hline Year & Cultivars & $\begin{array}{c}\text { Sowing dates } \\
\mathrm{mm} / \mathrm{dd}\end{array}$ & $\begin{array}{l}\text { Plant density } \\
\text { Seedlings/pots }\end{array}$ & $\begin{array}{c}\text { Transplanting } \\
\text { mm/dd }\end{array}$ & $\begin{array}{l}\text { Maximum tillering } \\
\mathrm{mm} / \mathrm{dd}\end{array}$ & $\begin{array}{l}\text { Full heading } \\
\mathrm{mm} / \mathrm{dd}\end{array}$ & $\begin{array}{r}\text { Maturity } \\
\mathrm{mm} / \mathrm{dd}\end{array}$ \\
\hline \multirow[t]{2}{*}{2016} & NPBA & $05 / 25$ & 6 seedlings & $06 / 23$ & $07 / 28$ & 08/16 & $10 / 10$ \\
\hline & LYP9 & $05 / 25$ & 6 seedlings & $06 / 23$ & 08/04 & $08 / 23$ & $10 / 20$ \\
\hline \multirow[t]{2}{*}{2017} & NPBA & $05 / 24$ & 6 seedlings & $06 / 22$ & $07 / 31$ & 08/19 & $10 / 13$ \\
\hline & LYP9 & $05 / 24$ & 6 seedlings & $06 / 22$ & 08/07 & $08 / 30$ & $10 / 17$ \\
\hline
\end{tabular}

NPBA, Nipponbare; LYP9, Laiangyoupeijiu.

as superphosphate $\left(\mathrm{P}_{2} \mathrm{O}_{5} 12 \%\right)$, and potassium was used as potassium sulfate $\left(\mathrm{K}_{2} \mathrm{O} 54 \%\right)$. The urea was used at the rate of $4.02 \mathrm{~g}$ and $5.24 \mathrm{~g}$ per pot in three splits; basal dose (50\%), top dressing at rice tillering stage (30\%), and top dressing at rice booting stage (20\%), respectively. The superphosphate (6.93 g per pot and $9.04 \mathrm{~g}$ per pot) was applied as a basal dose. Potassium sulfate ( $3.08 \mathrm{~g}$ per pot and $4.02 \mathrm{~g}$ per pot) was added in two splits, basally $(50 \%)$, and a top dressing at the rice booting stage (50\%) during 2016 and 2017, respectively.

\section{1-Methylcyclopropene Application}

Gassy 1-MCP was set free in granules (Fresh Doctor, Xianyang XiQin Biological Technology Co. Ltd). 1-MCP gas was released by dissolving the powdered formulation into the water. The 1MCP was applied at the mid-booting stage at $0.04 \mathrm{~g}$ per pot during 2016 and 2017. A plastic sheet was used to cover the pots after 1-MCP application to provide a closed environment for the reaction, and pots were uncovered for as long as $24 \mathrm{~h}$ (Harper, 2015; Sajid et al., 2018). The irrigated water level was sustained at about $2-4 \mathrm{~cm}$ in the pots, while 1-MCP was applied.

\section{Plant Sampling}

Plant samples from different treatments were collected and measured. The plant length, root length, leaf area and the dry matter (DM) at the rice full heading stage were measured. The ethylene of superior spikelets and inferior spikelets were collected with three replicates. Three plant samples were collected for measurement of the aboveground biomass at rice maturity stage. Flag leaves from five rice plants were sampled after 1MCP application with three replicates, and SOD, MDA, $\mathrm{H}_{2} \mathrm{O}_{2}$, chlorophyll a, b, carotenoids, proline, and soluble protein in rice flag leaves were measured every 10 days.

\section{Ethylene Extraction}

The ethylene production in spikelets was calculated following Beltrano et al. (1994) and Zhang et al. (2014). Thirty spikelets (superior and inferior spikelets) were separated from panicles and placed between two moist papers for $60 \mathrm{~min}$ at room temperature $\left(27^{\circ} \mathrm{C}\right)$ in the dark, to eliminate the ethylene trauma caused by cutting. The treated spikelets were shifted into a $70 \mathrm{~mL}$ glass vial and instantly wrapped with an airtight stopper. The samples were incubated in the dark for $24 \mathrm{~h}$ at $27^{\circ} \mathrm{C}$. A $1 \mathrm{~mL}$ gas sample was withdrawn from the vial using a syringe, and the concentration of ethylene was calculated by using gas chromatography (Agilent 7890A, Agilent Technologies Inc., United States) furnished with an FID (flame ionization detector) and column GS-GASPRO.
The temperature was kept at $160^{\circ} \mathrm{C}$, and $150^{\circ} \mathrm{C}$ for the detector, and the injection port was held constant. Nitrogen gas worked

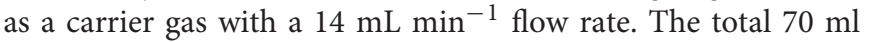
of the gas volume was used. The concentration of ethylene was calculated with pmol unit $\mathrm{g}^{-1}(\mathrm{FW}) \mathrm{h}^{-1}$.

\section{Measurement of Proline and Soluble Protein in Flag Leaf}

Soluble protein in rice flag leaves were measured according to the methods of Sedmak and Grossberg (1977) and Scopes (1987). The soluble protein solution extraction was absorbed into a tube, and $5 \mathrm{ml}$ of Coomassie brilliant blue G-250 (Bradford assay) staining fluid was added and thoroughly mixed. The tube was then set aside for $20 \mathrm{~min}$. For protein assays, Bovine serum albumin (BSA) was used as a standard. The absorbance was measured chronometrically (UV-2600, Shimadzu, Japan) at $595 \mathrm{~nm}$. Soluble protein was measured using the given formula:

$$
\text { Soluble Protein }(\mathrm{mg} / \mathrm{g} \text { fresh weight })=C \times \frac{\left(\frac{V}{v}\right)}{(w \times 1000)}
$$

Where, $C$ is the concentration of samples, $W(\mathrm{~g})$ is the fresh weight of samples used during measurement, $V(\mathrm{~mL})$ is the total volume of the extract, and $v(\mathrm{~mL})$ is the volume of extract added to the reaction.

Proline in flag leaves (about $0.2 \mathrm{~g}$ ) was extracted with $5 \mathrm{ml}$ of sulfosalicylic acid (3\%) in a boiling water bath for $30 \mathrm{~min}$. After that, filtrated extraction $(2 \mathrm{ml})$ was mixed with a ninhydrin reagent $(2 \mathrm{ml})$ and glacial acetic acid $(2 \mathrm{ml})$. This combination of the mixture was put at $100^{\circ} \mathrm{C}$ into boiling water for $30 \mathrm{~min}$ and then put on ice $\left(-4^{\circ} \mathrm{C}\right)$ for 20 min before extraction with toluene $(4 \mathrm{ml})$. The chromospheres absorbance in the toluene fraction was calculated colorimetrically at $520 \mathrm{~nm}$ using a UVVIS (Spectrophotometer Shimadzu). The amount of proline was determined by comparing it to a calibration curve prepared with an 1-proline solution. The proline was calculated using the following formula (Bates et al., 1973):

$$
\text { Proline contents }=C \times V \times \frac{2}{a \times w}
$$

Where $C$ is the concentration of the sample, $V$ is the volume of the extracted solution, $a$ is the standard solution, and $w$ is the weight of the sample. The unit of proline was used as $\mu \mathrm{Mg}^{-1} \mathrm{FW}$. 


\section{Chlorophyll Contents}

Chlorophyll contents (Chl $a, b$, and carotenoids) were extracted from fresh flag leaves using $25 \mathrm{~mL}$ of mixed acetone and alcohol ( $\mathrm{v}: \mathrm{v}=1: 1)$ for $24 \mathrm{~h}$ in the darkness at $25^{\circ} \mathrm{C}$. The absorbance of the sample was calculated at 663,645 , and $470 \mathrm{~nm}$ using a UV-VIS spectrophotometer (UV-2600, Shimadzu, Japan) to estimate the chlorophyll contents according to the methods by Wellburn and Lichtenthaler (1984) and Zhong et al. (2017).

The following formulas were used to calculate the $\mathrm{Chl} a, b$, carotenoids, and total chlorophyll:

$$
\begin{gathered}
\text { Chlorophyll } \mathrm{a}=12.21 \mathrm{A663}-2.81 \mathrm{~A} 645 \\
\text { Chlorophyll } \mathrm{b}=20.13 \mathrm{~A} 645-5.03 \mathrm{~A} 663 \\
\text { Carotenoids }=\frac{1000 \mathrm{~A} 470-3.27 \mathrm{Ca}-104 \mathrm{Cb}}{229}
\end{gathered}
$$

Total Chlorophyll contents $=\mathrm{Chl} \mathrm{a}+\mathrm{Chl} \mathrm{b}+$ Carotenoids

The unit for chlorophyll contents was used as mg.g ${ }^{-1} \mathrm{FW}$.

\section{Determination of Antioxidants \\ SOD in Rice Flag Leaves}

Frozen flag leaf samples were crushed in liquid nitrogen and mixed with a $6 \mathrm{ml}$ sodium phosphate buffer $(\mathrm{pH}$ 7.8). This mixture was centrifuged at $6000 \mathrm{rpm}$ for $10 \mathrm{~min}$ at $4^{\circ} \mathrm{C}$, and the supernatant was put in storage at $-70^{\circ} \mathrm{C}$ for the measurement of soluble protein, SOD, and MDA. SOD activity was assayed by employing the methodology of Giannopolitis and Ries (1977) and Agarwal and Pandey (2004). The SOD reaction system contained $25 \mathrm{mmol} \mathrm{NaH}_{2} \mathrm{PO}_{4}$ buffer, $13 \mathrm{mmol}$ methionine, $10 \mu \mathrm{mol} / \mathrm{L}$ riboflavin, $100 \mu \mathrm{mol} / \mathrm{l}$ EDTA-Na, $750 \mu \mathrm{mol} / \mathrm{l}$ nitro blue tetrazolium (NBT), and a $0.1 \mathrm{~mL}$ enzyme extraction was added to the reaction. Samples were put under light $(4000 \mathrm{~lx})$ for $20 \mathrm{~min}$, and the absorbance was calculated chronometrically at $560 \mathrm{~nm}$. The blank replaced the extract with a sodium phosphate buffer and was placed in darkness. SOD action was demarcated as the enzymatic amount that would obstruct a $50 \%$ photoreduction of nitro blue tetrazolium (NBT) chloride. The unit of SOD used was $\mu \mathrm{g}^{-1} \mathrm{FW} \mathrm{h}{ }^{-1}$. The SOD activity was calculated using the following equation:

$$
S O D \text { activty }=(O D c-O D s) \times \frac{v}{(0.5 \times O D c \times V s \times m)}
$$

Which includes $O D c$ (ODc of control tube), ODs (ODs of sample tube), $V(\mathrm{~mL})$ (volume of enzyme extraction), $V s(\mathrm{~mL})$ (volume of enzyme extraction added to reaction), and $m$ (g) (weight of sample).

\section{Malondialdehyde in Rice Flag Leaves}

The methods of Velikova et al. (2000) measured the MDA value in flag leaves of rice. A tube consisting of $1 \mathrm{ml}$ extract and $2 \mathrm{ml}$ thiobarbituric acid (TBA, $0.5 \%$ ) in $0.5 \%$ trichloroacetic acid
(TCA) was placed in boiling water to react for $15 \mathrm{~min}$. The absorbance was measured chronometrically (UV-2600, UV-VIS Spectrophotometer Shimadzu) at 450, 532, and $600 \mathrm{~nm}$. The quantity of the MDA-TBA complex was determined from the extinction coefficient at $155 \mathrm{mmol} \mathrm{L}^{-1}$. The MDA was calculated as $\mu \mathrm{mol} / \mathrm{g}$ fresh weight.

$$
C=6.46 \times(D 532-D 600)-0.56 \times D 450
$$

Where D450, 532, and 600 are wavelengths, and

$$
M D A=C \times 4 \times 2.5 /(1.55 \times W)
$$

Where $C$ is the concentration at a different wavelength, and $W$ is the sample weight.

\section{$\mathrm{H}_{2} \mathrm{O}_{2}$ in Flag Leaves}

$\mathrm{H}_{2} \mathrm{O}_{2}$ values were calculated using previous methods by Brennan and Frenkel (1977) and Yang et al. (2007). About $0.1 \mathrm{~g}$ frozen flag leaves were crushed in liquid nitrogen and mixed with $3 \mathrm{~mL}$ of $10 \mathrm{mM} \mathrm{3-amino-1,2,4-triazole.} \mathrm{The} \mathrm{extract} \mathrm{was} \mathrm{centrifuged}$ at $8000 \mathrm{rpm}$ for $10 \mathrm{~min}$ at $4^{\circ} \mathrm{C}$. After centrifugation, $2 \mathrm{~mL}$ supernatant extract and $1 \mathrm{~mL}$ titanium sulfate $(0.1 \%)$ in $20 \%$ sulfuric acid was mixed in $10 \mathrm{~mL}$-centrifuge tubes. The samples were placed at room temperature for $10 \mathrm{~min}$, the mixture was centrifuged again at $8000 \mathrm{rpm}$ for $10 \mathrm{~min}$ at $4^{\circ} \mathrm{C}$. The supernatant extract was calculated calorimetrically at $410 \mathrm{~nm}$. A standard curve was obtained using $30 \% \mathrm{H}_{2} \mathrm{O}_{2}$ as a standard.

$$
\mathrm{H} 2 \mathrm{O} 2=\frac{\mathrm{C}^{*}(\mathrm{~V} / \mathrm{Vs})}{\mathrm{W}}
$$

Where $C$ is absorbance, $V$ is total volume, $V s$ is extracted volume, and $W$ is leaf sample weight. The unit of $\mathrm{H}_{2} \mathrm{O}_{2}$ was used as $\mu$ mol.g ${ }^{-1} \mathrm{FW}$.

\section{Physiological Parameters Photosynthesis}

The net photosynthesis rate $\left(\mathrm{P}_{\mathrm{n}}\right)$ of the flag leaf was recorded at the rice full heading stage after 1-MCP application. The photosynthesis data were recorded using a portable photosynthesis system (LI-6400XT, LI-COR Company, United States) on sunny days between 8:30 am to 11:30 am. In the leaf chamber, the $\mathrm{CO}_{2}$ concentration was kept at $400 \mu \mathrm{mol}$ $\mathrm{mol}^{-1}$. The temperature was set at $30^{\circ} \mathrm{C}$, and the light intensity was set to $1500 \mu \mathrm{mol} \mathrm{Em}^{-2} \mathrm{~S}^{-1}$, at the time of recording.

\section{SPAD Value}

Ten rice plants were selected to measure chlorophyll contents (SPAD values) at the rice full heading stage. The reading was taken at 7 days intervals, from the same plants. SPAD values of the rice flag leaves were measured three times after application of $1-M C P$ by a SPAD meter (SPAD-502 plus).

\section{Aboveground Biomass and Grain Yield}

Three plant samples were harvested at maturity, to measure the total aboveground biomass. The plants were harvested carefully from the near soil surface and placed in room temperature until samples gained a constant weight. Three plant samples were harvested for calculating the grain yield. 


\section{Quality Assurance}

Our laboratory, the State Key Laboratory of Rice Biology in China, is ranked as an international laboratory. The integrity of our laboratory systems is routinely audited and certified by the British standards institution and meet all applicable requirements of the ISO9001 standard. All chemicals were purchased by the Aladdin Industrial Corporation, Shanghai, China and the SigmaAldrich Corporation China, and the purity level was 99\%.

\section{Statistical Analysis}

This experimental design used was a completely randomized design (CRD). Statistical analysis of the data was compiled using standard analyses of variance (Two-way ANOVA). The comparison of mean values was made using the least significant difference (LSD) at the level of significance (5\%) using SPSS Statistics (19.0 software package).

\section{RESULTS}

\section{1-MCP Modulated Physiological Characters of Rice Under Salt Stress Net Photosynthesis Rate}

Salt stress in soil decreased the $P_{n}$ values in rice flag leaves for both LYP9 and NPBA (Figures 1A-D). In comparison with the CK group, the $\mathrm{P}_{\mathrm{n}}$ value for LYP9 was 2.3, 8.4, and $25.1 \%$ lower in the LS, MS, and HS treatments, respectively. In NPBA, the $\mathrm{P}_{n}$ value was 2 and $3.4 \%$ higher in LS and MS, compared to CK, respectively. The application of $1-\mathrm{MCP}$ significantly improved the $P_{n}$ value in rice flag leaves under salt stress, compared with no usage of 1-MCP in both rice cultivars (Figures 1A-D). However, in LYP9, the average $P_{n}$ in rice flag leaves was $8.1 \%(C K), 13.1 \%$ (LS), $14.6 \%(\mathrm{MS})$, and $14.2 \%(\mathrm{HS})$, higher in leaves that received 1-MCP compared to those that received no 1-MCP, respectively (Figures 1A,C). The $P_{n}$ value of LYP9 flag leaves showed a significant difference between increased salt stress treatments (MS and HS).

For NPBA, the $P_{n}$ value of flag leaves were considerably lower with increased salt stress levels. The average $\mathrm{P}_{\mathrm{n}}$ of rice flag leaves were $12.9 \%(\mathrm{CK}), 19.9 \%(\mathrm{LS})$, and $14.3 \%(\mathrm{MS})$ higher in leaves that received 1-MCP compared to those that received no 1MCP (Figures 1B,D). These results revealed that 1-MCP had significant effects on increasing the $\mathrm{P}_{\mathrm{n}}$ value of rice flag leaves in the CK and LS treatments, but had no significant effects in the MS level. This could be an intrinsic factor of the NPBA cultivar in response to salt stress.

Overall, 2 years of data revealed that the value of $P_{n}$ in flag leaves was higher in LYP9 than in NPBA under salt stress, and that NPBA could not survive at the HS level. A high $P_{n}$ value is a source of high carbohydrate formation. In previous studies, due to salt stress, the production of carbohydrates was reduced (Parida and Das, 2005), which ultimately led to a reduction in rice grain yield. Application of 1-MCP improved the $P_{n}$ value of flag leaves in both NPBA and LYP9, even under salt stress conditions. The results showed that 1-MCP has the potential to assimilate carbohydrates in rice leaves, and that it can improve important physiological parameters in rice plants, such as photosynthesis in adverse environments (Figures 1A-D). These findings confirmed the affinity of 1-MCP to improve assimilation of carbohydrates in rice leaves, by enhancing key parameters related to physiology, such as $P_{n}$ under adverse salt stress.

\section{SPAD Value}

Chlorophyll contents were represented as SPAD values of the flag leaf in this experiment (Esfahani et al., 2008). The LYP9 and NPBA showed a variation in SPAD values in response to salt stress levels (Figures 1E-H). The average of 2 years of data showed that SPAD values in LYP9 decreased by 1.9 and $5.6 \%$ in LS and MS levels, compared with CK, respectively. The SPAD values in rice flag leaves were improved by $7.8 \%$ (CK), $4.0 \%(\mathrm{MS})$, and $8.8 \%(\mathrm{HS})$, respectively after $1-\mathrm{MCP}$ application, compared to no 1-MCP in LYP9 (Figures 1E,G).

Whereas, in the NPBA, SPAD values in rice flag leaves reduced by 2.5 and $6 \%$ in LS and MS, respectively, compared with the CK. SPAD values in flag leaves were enhanced by $5.7,6.7$, and $8.5 \%$ in the CK, LS, and HS, respectively, with 1-MCP usage, compared to no 1-MCP in NPBA. These outcomes support that 1-MCP has important effects on delaying the senescence of rice leaves. NPBA showed a high sensitivity to the HS level and could not survive HS treatment (Figures 1F,H).

The variation of SPAD values between LYP9 and NPBA flag leaves, may be endorsed by the inherent genetic variabilities of both rice cultivars (Figures 1E-H). By comparing LYP9 and NPBA, LYP9 showed higher SPAD values in flag leaves that received 1-MCP, under all salt stress levels, than those for NPBA. The results suggest that 1-MCP has a significant effect on deferring the senescence of flag leaves. The LYP9 showed susceptibility under the adverse condition of HS treatment.

\section{1-MCP Modulated Biochemical Characteristics \\ Ethylene Production}

Biosynthesis of ethylene was enhanced in rice spikelets with increased salt stress levels. The release of ethylene in spikelets of LYP9 was higher than that in NPBA, under salt stress conditions. These findings revealed that the high concentration of ethylene in rice spikelets was considerably increased with the increased salt levels in LYP9. The same trend was shown in NPBA under CK, LS, and MS, but seedlings for NPBA at HS could not survive. The average ethylene production, from 2-years of data, in spikelets of LYP9 was significantly increased by 46, 109, and $85.8 \%$ at LS, MS, and HS, respectively, compared to the control. After usage of 1-MCP, the biosynthesis of ethylene in spikelets was decreased by $40.2 \%$ (CK), $44.3 \%$ (LS), $28 \%$ (MS), and $27.4 \%(\mathrm{HS})$, respectively, compared to plants without 1-MCP application (Figures 2A-D).

In the case of NPBA, the ethylene concentration was significantly increased with increasing salt levels. The increasing rate of ethylene production in spikelets, after exposure to salt stress, was 38 and $65.5 \%$ at LS and MS, respectively, compared to CK. Ethylene production in spikelets of NPBA with 1-MCP was lower at $23.9 \%$ (CK), $28.6 \%$ (LS), and $25.9 \%$ (MS) for stress levels compared to no 1-MCP treatment (Figures 2A-D). 


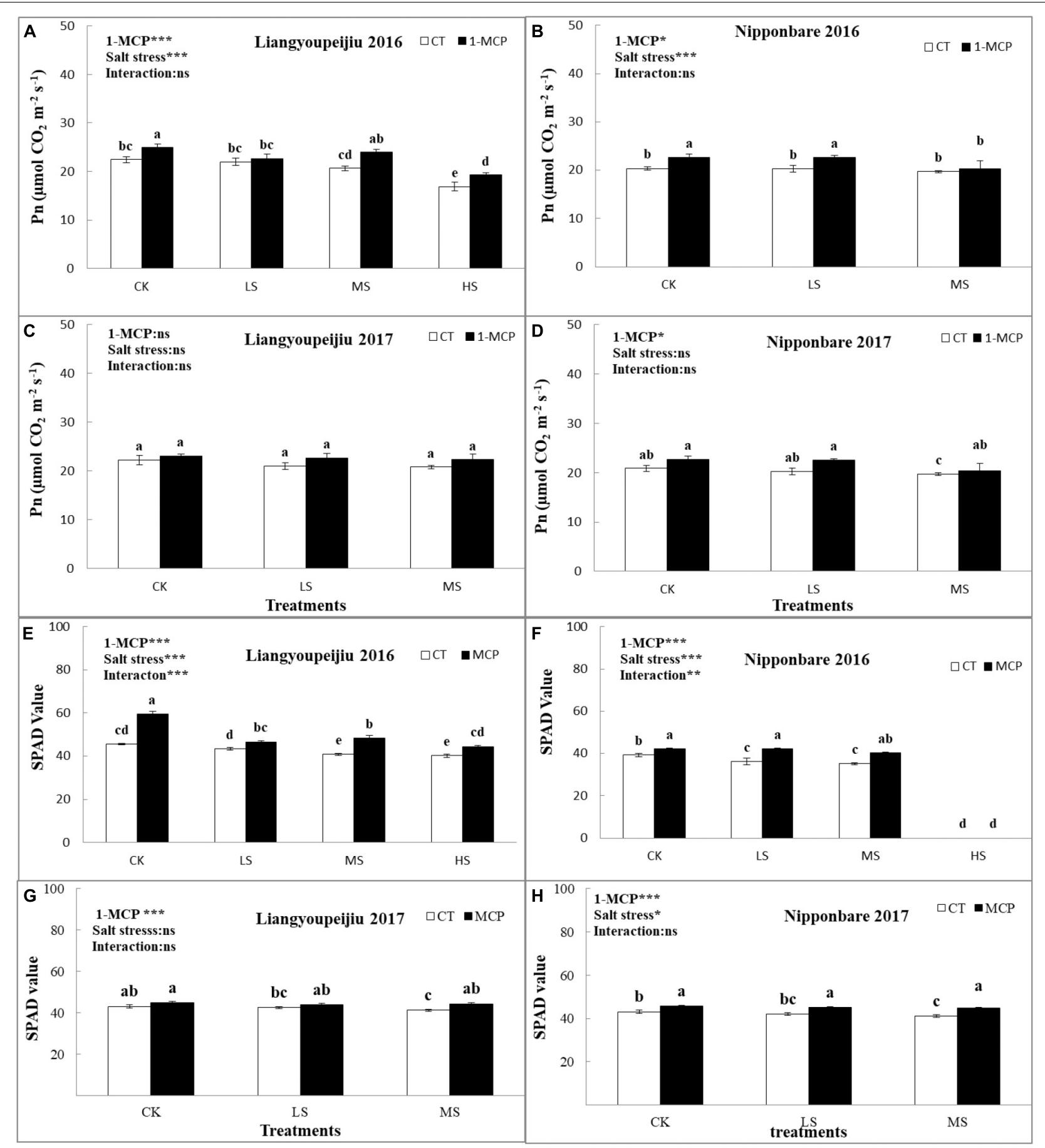

FIGURE 1 | Comparison effects of 1-MCP and salt levels on net photosynthesis rate, $P_{n}$ (A-D) and SPAD values (E-H) of rice flag leaves in 2016 and 2017 . Values are denoted as mean $\pm \mathrm{SE}\left(\mathrm{P}_{\mathrm{n}}, n=3\right.$ and SPAD, $\left.n=5\right)$. Values followed by different letters are significantly different $(p \leq 0.05)$ according to the LSD test. Where treatments are Control (CK), Low Salt Stress (LS), and Medium Salt Stress (MS), while CT = no 1-MCP treatment and 1-MCP = 1-MCP treatment. Liangyoupeijiu (LYP9) and Nipponbare (NPBA) are rice cultivars. P-values of the two-way ANOVAs of 1-MCP, salt stress, and their interaction are indicated: ns, not significant; ${ }^{*} P<0.05 ;{ }^{* *} P<0.01 ;{ }^{* * *} P<0.001$. Bars with the same letter are not significantly different in the LSD test.

The impact of 1-MCP on reducing ethylene inhibition in spikelets of NPBA were lower than that of LYP9, under salt stress.
Ethylene biosynthesis in both LYP9 and NPBA spikelets with 1-MCP application, was significantly decreased than no 1-MCP level. 1-MCP proved its potential to inhibit 


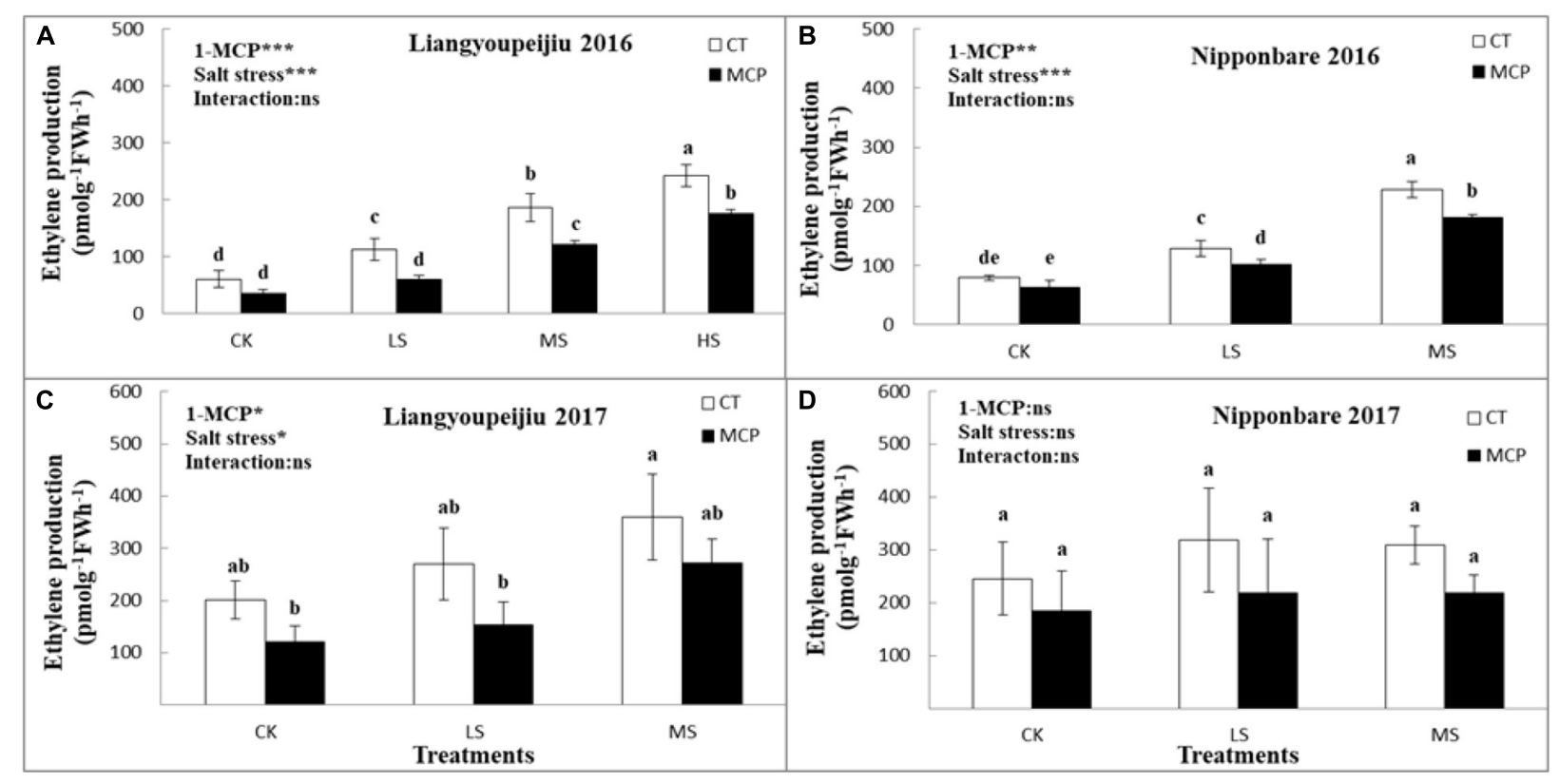

FIGURE 2 | Comparison of effects of 1-MCP and salt levels on ethylene production in spikelets of rice (A-D) in 2016 and 2017. Values are denoted as mean \pm SE $(n=6)$. Values followed by different letters are significantly different $(p \leq 0.05)$ according to the LSD test. Where treatments are Control (CK), Low Salt Stress (LS), and Medium Salt Stress (MS), while CT $=$ no 1-MCP treatment and 1-MCP $=1-\mathrm{MCP}$ treatment. Liangyoupeijiu (LYP9) and Nipponbare (NPBA) are rice cultivars. $P$-values of the two-way ANOVAs of 1-MCP, salt stress, and their interaction are indicated: ns, not significant; ${ }^{*} P<0.05 ;{ }^{* *} P<0.01 ;{ }^{* * *} P<0.001$. Bars with the same letter are not significantly different in the LSD test.

ethylene action in rice under the salinity condition. The outcomes revealed that the ethylene biosynthesis in spikelets of LYP9 was more than in NPBA; this variation could be associated with the genetic variation of the cultivar response to salt stress.

\section{Proline Contents in Flag Leaf}

The proline contents in rice flag leaves were increased in both the LYP9 and NPBA with increasing salt levels over 2 years of experiments. In both rice cultivars, salt stress induced a boost in proline content, regardless of the tolerance to salt stress. For LYP9, the proline content in flag leaves showed significant differences between the four salt stress levels (CK, LS, MS, and HS; Figures 3A-D). The proline content in the LYP9 was 17.1$57.5 \%$ higher for LS than for CK, 23.7-62.5\% higher for MS than for CK, and $9.2 \%$ higher for HS than for CK, respectively. After 1-MCP application, the proline contents were decreased by $4.3-$ $22.4 \%$ (CK), 30.3-43.5\% (LS), and 46.6-38.3\% (MS), and 38.3\% (HS), respectively, in comparison with LYP9 plants without 1MCP application.

Whereas in the case of NPBA, the range of proline contents under salt stress was $8.6-15.7 \%$ (LS) and $26.4-30 \%$ (MS) higher than those for CK. When 1-MCP was applied, the proline contents were decreased by $12.8-17.4 \%, 19.128 .9 \%$, and 23.6-47.9\%, respectively, in the CK, LS, and MS groups compared to the NPBA plants with no 1-MCP. There was a steady decrease in proline contents in the flag leaves of LYP9 under salt stress from CK to HS. After the 1-MCP application, proline contents in flag leaves decreased in both
NPBA and LYP9 under salt stress. The results clearly showed that LYP9 and NPBA induced higher proline accumulation under the salinity condition. This might play a vital role for salt stress tolerance in rice cultivars. The results suggest that LYP9 and NPBA induce higher proline accumulation in a salty environment.

\section{Soluble Protein in Rice Flag Leaf}

I general, the soluble protein content in rice flag leaves were lower with increased salt stress levels (Figures 3E-H). Compared with $\mathrm{CK}$, the soluble protein content of LYP9 decreased by $10.3,8.3$, and $38.2 \%$ in the LS, MS, and HS, respectively. Total soluble protein contents of LYP9 increased after 1-MCP application by 16.3-43\% (CK), 31.4$87.4 \%$ (LS), $54.6-73.7 \%$ (MS), and $10.8 \%$ (HS), respectively, in comparison to the a comparison LYP9 group without 1MCP. Compared with CK, the average soluble protein content of NPBA was lowered by $15.9 \%$ (LS) and 34\% (MS), with increased salt stress levels. The total soluble protein content of NPBA was improved by $22.8 \%$ (CK), $20.6 \%$ (LS), and $76.5 \%$ (MS), respectively, after 1-MCP application compared to that of NPBA plants without 1-MCP application. Collectively, total soluble protein contents were higher in LYP9 than in NPBA under all salt levels. Total protein contents were higher in LYP9 than in NPBA under LS and HS salt stress (Figures 3E-H). Comparatively, LYP9 showed better results than NPBA did, due to different responses to salt stress after 1-MCP application. 


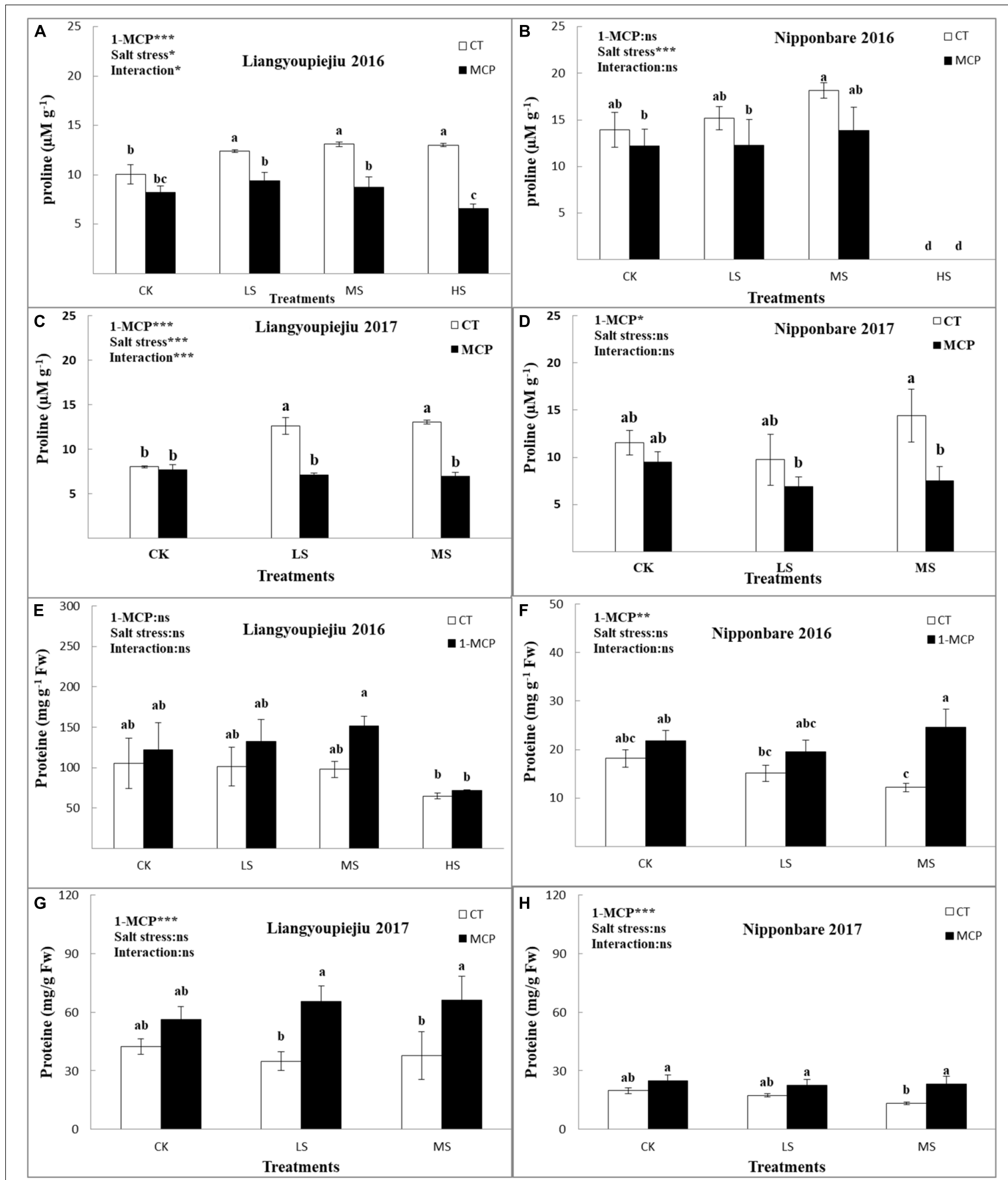

FIGURE 3 | Comparison effects of 1-MCP and salt levels on proline contents (A-D) and protein contents (E-H) of rice flag leaf in 2016 and 2017. Values are denoted as mean \pm SE $(n=4)$. Values followed by different letters are significantly different $(p \leq 0.05)$ according to LSD test. Where treatments are Control (CK), Low Salt Stress (LS), and Medium Salt Stress (MS), while CT = no 1-MCP treatment and 1-MCP = 1-MCP treatment. Liangyoupeijiu (LYP9) and Nipponbare (NPBA) are rice cultivars. $P$-values of the two-way ANOVAs of 1-MCP, salt stress, and their interaction are indicated: ns, not significant; ${ }^{*} P<0.05 ;{ }^{* *} P<0.01 ;{ }^{* * *} P<0.001$. Bars with the same letter are not significantly different by LSD test. 


\section{Chlorophyll Contents (Chl a, $b$, Carotenoids, and Total Chlorophyll)}

Total chlorophyll contents (Chl $a, b$, carotenoids) decreased with increased salt stress levels (Table 2). Compared with no 1-MCP application, the chlorophyll $a, b$, carotenoids, and total chlorophyll content increased by $7.7,20,14.3$, and $10.6 \%$ for CK, 20, 22.5, 16.7, and 20\% for LS, and 29.9, 35.6, 15.9, and $28.4 \%$ for MS, respectively in LYP9. Whereas in NPBA, the total chlorophyll contents such as chl $a, b$, and carotenoids increased by $11.1,3.8,36.5$, and $13.8 \%$ for CK, $18,13.7,6.4$, and $14 \%$ for LS, and 16.2, 44.7, 8.2, and $19.5 \%$ for MS, respectively, compared with no 1-MCP application. Total protein contents were higher in LYP9 than in NPBA in the LS and MS controls. Comparatively, LYP9 showed better results than NPBA did, because of a different response to salt levels. These results reveal that the sensitive nature of NPBA compared to LYP9. Chlorophyll contents are the basic indicators of photosynthesis activity in rice leaves. Low chlorophyll contents are one of the major causes of low growth and yield production for rice plants (Table 2).

\section{1-MCP Modulated Antioxidant Characteristics Superoxide Dismutase Activity}

Among the enzymatic antioxidants, SOD is a key superoxide scavenger due to its enzymatic activity (Sharma et al., 2012). The results showed that SOD activity in flag leaves was decreased under all salt stress levels relative to $\mathrm{CK}$ in both rice cultivars. Compared to the SOD activity of CK, the SOD activity of LS decreased by $6.7 \%$, MS decreased by $15.4 \%$, and HS decreased by $42.7 \%$, respectively (Figures 4 A-D). 1-MCP usage improved the average SOD contents by $7.2 \%$ for CK, $8.9 \%$ for LS, $24.5 \%$ for MS, and $33.2 \%$ for HS, respectively, compared to LYP9 plants without $1-\mathrm{MCP}$ application. In NPBA, the SOD activity under salt stress was $2 \%$ (LS) and 7.6\% (MS) lower than CK. The average total SOD contents were improved by $4.7 \%$ (CK), $11.3 \%$ (LS), and $14.2 \%$ (MS) with 1-MCP application, compared to NPBA plants without 1-MCP application. The decreasing rate was significantly higher in LYP9 than in NPBA under salt stress. By using 1-MCP, LYP9 showed a better response than NPBA to increasing SOD contents. Decreased SOD activity under salt stress might be the most important cause of dominant membrane damage, oxidative stress, and enhanced MDA contents.

\section{Malondialdehyde}

Two-years of experiments revealed that increased MDA was observed with increased salt concentrations from LS to HS in LYP9, and from LS to MS in NPBA. The MDA contents in LYP9 increased by $20.2 \%$ (LS) and $27.5 \%$ (MS), respectively. MDA contents for LYP9 were lower after 1-MCP application by $13 \%$ (CK), 25.4\% (LS), 33.5\% (MS), and 35.6\% (HS), respectively, compared to LYP9 plants without the level of 1-MCP to compare with CK. While in comparison with $\mathrm{CK}$, the MDA contents in NPBA increased by $10.5 \%$ (LS) and $15.8 \%$ (MS) with increased salt stress levels. MDA contents in NPBA were lower after 1MCP application by $13.1 \%$ (CK), $25.1 \%$ (LS), and $31.4 \%$ (MS), respectively, compared to NPBA plants without a 1-MCP level. MDA contents were higher in LYP9 than in NPBA under all salt stress levels.

Salt stress induced a boost in MDA contents in both rice cultivars, regardless of their tolerance to salt stress. For LYP9 and

TABLE 2 | Effects of 1-MCP on chlorophyll contents (Chl a, b, carotenoids, and total chl contents) in 2017.

\begin{tabular}{|c|c|c|c|c|c|c|}
\hline Cultivars & Salt levels & PGR & $\begin{array}{l}\text { Chlorophyll a } \\
\mathrm{mg} \mathrm{g}^{-1} \mathrm{Fw}\end{array}$ & $\begin{array}{l}\text { Chlorophyll } b \\
\mathrm{mg} \mathrm{g}^{-1} \mathrm{Fw}\end{array}$ & $\begin{array}{l}\text { Carotenoid } \\
\mathrm{mg} \mathrm{g}^{-1} \mathrm{Fw}\end{array}$ & $\begin{array}{l}\text { Total chlorophyll } \\
\mathrm{mg} \mathrm{g}^{-1} \mathrm{Fw}\end{array}$ \\
\hline \multirow[t]{9}{*}{ LYP9 } & CK & 1-MCP & $2.8 \pm 0.1 \mathrm{ab}$ & $0.6 \pm 0.03 a$ & $0.8 \pm 0.01 a b$ & $4.2 \pm 0.01 a$ \\
\hline & & $\mathrm{CT}$ & $2.6 \pm 0.1 b$ & $0.5 \pm 0.02 \mathrm{ab}$ & $0.7 \pm 0.03 a b$ & $3.8 \pm 0.01 \mathrm{ab}$ \\
\hline & LS & 1-MCP & $2.8 \pm 0.2 \mathrm{ab}$ & $0.6 \pm 0.1 a$ & $0.8 \pm 0.1 \mathrm{a}$ & $4.2 \pm 0.01 \mathrm{a}$ \\
\hline & & $\mathrm{CT}$ & $2.4 \pm 0.1 c$ & $0.5 \pm 0.03 b$ & $0.7 \pm 0.04 a b$ & $3.5 \pm 0.01 b$ \\
\hline & MS & 1-MCP & $3.0 \pm 0.1 a$ & $0.6 \pm 0.02 a$ & $0.7 \pm 0.1 \mathrm{ab}$ & $4.3 \pm 0.01 a$ \\
\hline & & CT & $2.3 \pm 0.2 c$ & $0.5 \pm 0.04 b$ & $0.6 \pm 0.03 b$ & $3.4 \pm 0.01 b$ \\
\hline & F Value & 1-MCP & $22.9^{* * *}$ & $17.16^{* * *}$ & $7.25^{* *}$ & $22.9^{* * *}$ \\
\hline & & Salt Stress & $0.54 \mathrm{~ns}$ & $0.47 \mathrm{~ns}$ & $0.82 \mathrm{~ns}$ & $0.51 \mathrm{~ns}$ \\
\hline & & Interaction & $1.6 \mathrm{~ns}$ & $0.86 \mathrm{~ns}$ & $0.46 \mathrm{~ns}$ & 1.44 ns \\
\hline \multirow[t]{9}{*}{ NPBA } & CK & 1-MCP & $3.3 \pm 0.1 a$ & $0.6 \pm 0.04 \mathrm{bc}$ & $0.9 \pm 0.03 a$ & $4.7 \pm 0.1 a$ \\
\hline & & CT & $2.97 \pm 0.05 b$ & $0.5 \pm 0.03 \mathrm{bc}$ & $0.6 \pm 0.04 b$ & $4.1 \pm 0.1 b$ \\
\hline & LS & 1-MCP & $2.69 \pm 0.1 b c$ & $0.6 \pm 0.02 b$ & $0.7 \pm 0.02 b$ & $3.9 \pm 0.1 b$ \\
\hline & & CT & $2.28 \pm 0.05 \mathrm{de}$ & $0.5 \pm 0.02 \mathrm{bc}$ & $0.6 \pm 0.05 b$ & $3.4 \pm 0.05 c$ \\
\hline & MS & 1-MCP & $2.51 \pm 0.1 \mathrm{~cd}$ & $0.7 \pm 0.02 a$ & $0.7 \pm 0.01 b$ & $3.86 \pm 0.2 b$ \\
\hline & & $\mathrm{CT}$ & $2.16 \pm 0.2 e$ & $0.5 \pm 0.04 \mathrm{c}$ & $0.6 \pm 0.1 b$ & $3.23 \pm 0.2 c$ \\
\hline & F Value & 1-MCP & $17.5^{* * *}$ & $15.78^{* * *}$ & $8.8^{* * *}$ & $25.65^{* * *}$ \\
\hline & & Salt Stress & $3.8^{*}$ & $0.87 \mathrm{~ns}$ & $3.9 *$ & $3.5^{*}$ \\
\hline & & Interaction & $28.16^{* * *}$ & $5.6^{* * *}$ & $2.9 \mathrm{~ns}$ & $17.3^{* * *}$ \\
\hline
\end{tabular}

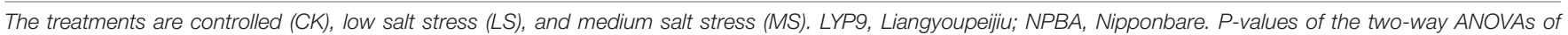

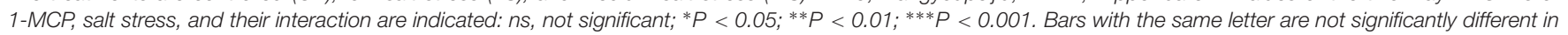
the $L S D$ test and $n=6$. 


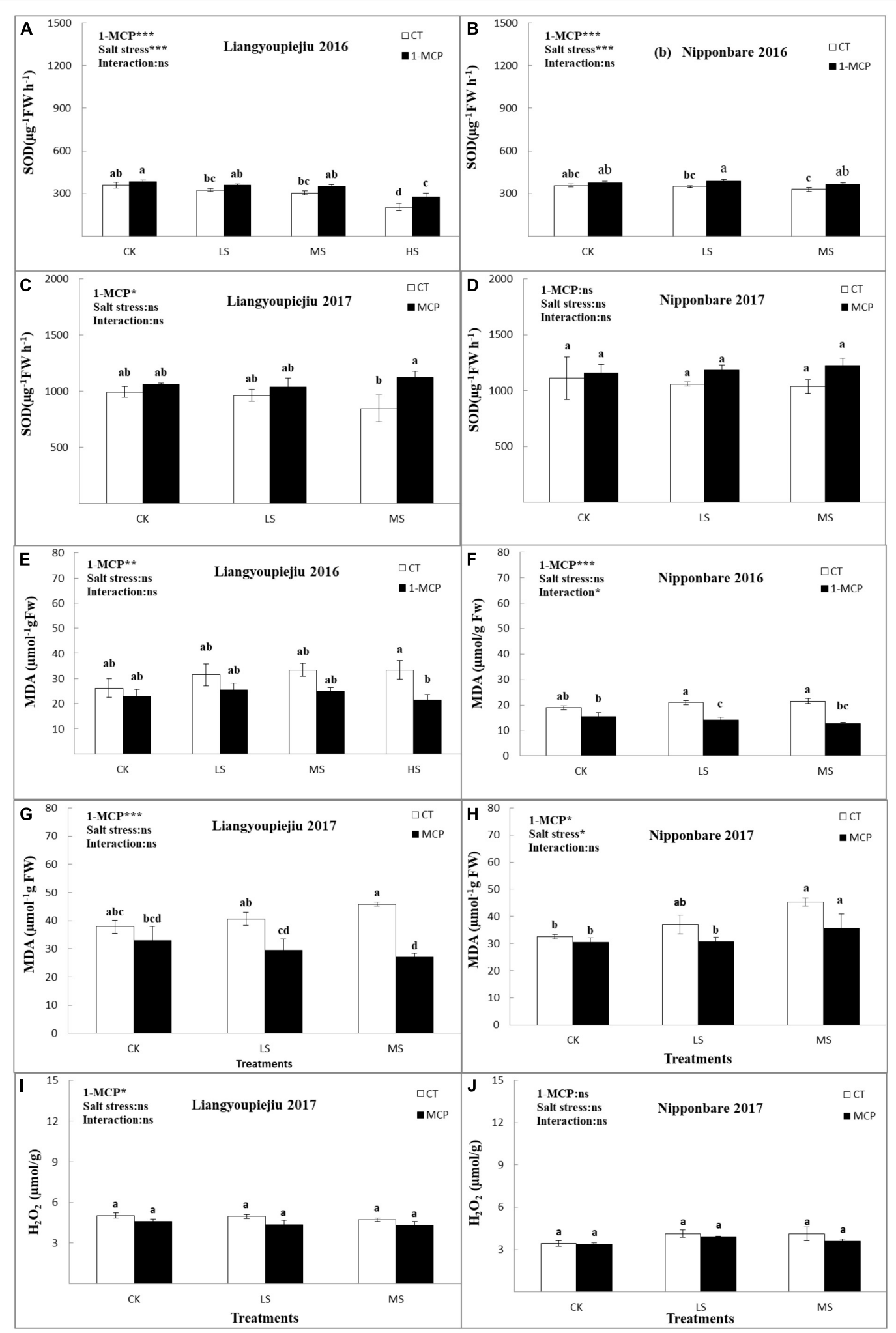

FIGURE 4 | Comparison effects of 1-MCP and salt levels on SOD (A-D), MDA (E-H), and $\mathrm{H}_{2} \mathrm{O}_{2}$ (I,J) of rice flag leaf in 2016 and 2017 . Values are denoted as mean \pm SE $(n=4)$. Values followed by different letters are significantly different $(p \leq 0.05)$ according to LSD test. Where treatments are Control (CK), Low Salt Stress (LS), and Medium Salt Stress (MS), while CT = no 1-MCP treatment and 1-MCP = 1-MCP treatment. Liangyoupeijiu (LYP9) and Nipponbare (NPBA) are rice cultivars. $P$-values of the two-way ANOVAs of 1-MCP, salt stress, and their interaction are indicated: ns, not significant; $* P<0.05 ;{ }^{* *} P<0.01 ;{ }^{* * *} P<0.001$. Bars with the same letter are not significantly different by LSD test. 
NPBA, the MDA contents showed a significant difference at the LS, MS, and HS levels compared to CK (Figures 4E-H). After the application of 1-MCP, MDA contents were decreased in both LYP9 and NPBA under CK, LS, MS, and HS levels. These results clearly showed that LYP9 induced higher MDA accumulation under salt stress conditions than NPBA did, which may have played a role in salt stress tolerance. However, reduced MDA contents was greater in NPBA compared to LYP9 after 1-MCP application. This variation is dependent on the genetic behavior and sensitivity of NPBA compared to the LYP9, in reaction to salt stress. These findings revealed that LYP9 might tolerate salt stress-induced oxidative damage better than NPBA.

\section{Hydrogen Peroxide}

Data from 2017 showed that $\mathrm{H}_{2} \mathrm{O}_{2}$ increased with increased salt concentrations in LYP9 and NPBA. After 1-MCP application, the $\mathrm{H}_{2} \mathrm{O}_{2}$ contents in LYP9 lowered by $8.5 \%$ (CK), $11.9 \%$ (LS), and 9.1\% (MS), respectively, compared with no 1-MCP application. $\mathrm{H}_{2} \mathrm{O}_{2}$ contents in NPBA were lower after 1-MCP application by $1.5 \%(\mathrm{CK}), 5.3 \%(\mathrm{LS})$, and 5.6\% (MS), respectively, compared with no 1-MCP application (Figures 4I,J).

For LYP9 and NPBA, the $\mathrm{H}_{2} \mathrm{O}_{2}$ contents showed a significant difference at the LS and MS levels compared to CK (Figures 4I,J). After the application of 1-MCP, $\mathrm{H}_{2} \mathrm{O}_{2}$ contents were decreased in both LYP9 and NPBA under CK, LS and MS levels. However, reduced $\mathrm{H}_{2} \mathrm{O}_{2}$ contents was greater in LYP9 compared to NPBA, after 1-MCP usage. These results indicate that LYP9 can tolerate salt stress-induced oxidative damage better than NPBA.

\section{Total Aboveground Biomass}

During the 2016-2017 rice growing seasons, salt stress greatly affected rice growth and total biomass production (Figures 5A-D). The total aboveground biomass in LYP9 was lowered by $12.6,37.9$, and $55.6 \%$ at the LS, MS, and HS levels, respectively, compared to $\mathrm{CK}$. The total aboveground biomass for LYP9 was improved after 1-MCP application by $12.1 \%(\mathrm{CK})$, $12.4 \%$ (LS), $27.6 \%$ (MS), and 17\% (HS), respectively, compared to without 1-MCP application.

Total above ground biomass in NPBA was also significantly lowered by $9.6 \%$ (LS) and $53.6 \%$ (MS) compared to CK. Total aboveground biomass for NPBA was higher after 1-MCP application by $11.5 \%$ (CK), $14.2 \%$ (LS), and $47.1 \%$ (MS), compared to plants without a 1-MCP level. The reduction in aboveground biomass was noticeably higher in NPBA, perhaps due to its salt sensitivity feature (Figures 5A-D). In comparison, 1-MCP significantly improved the total aboveground biomass in both rice cultivars. This might be because of a high response to 1-MCP in NPBA (a salt sensitive cultivar).

The effect of 1-MCP on increasing the total aboveground biomass was more obvious for LYP9 than for NPBA under salt stress conditions. These variations in total aboveground biomass

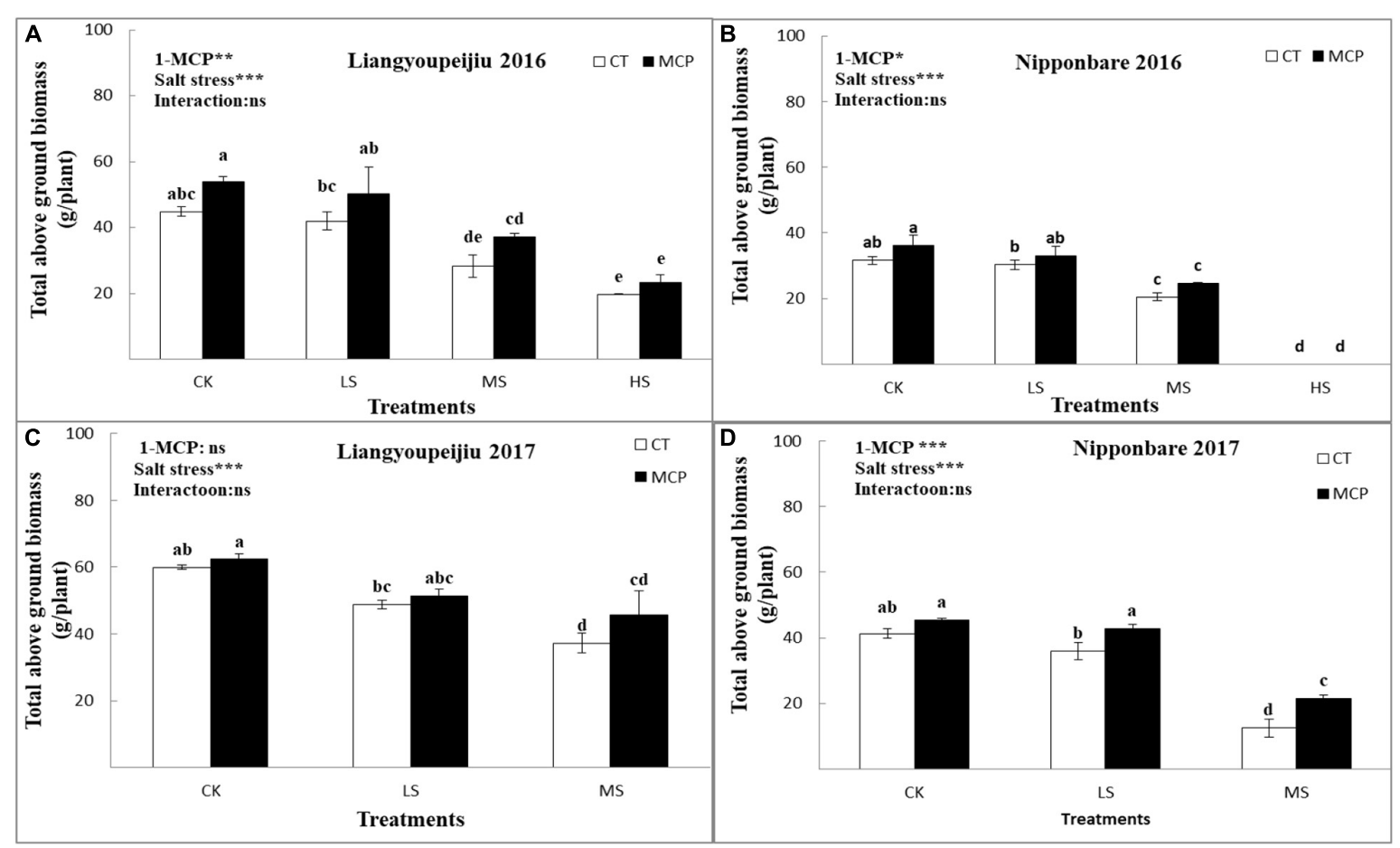

FIGURE 5 | Comparison effects of 1-MCP and salt levels on total above ground biomass (A-D) of rice flag leaves in 2016 and 2017. Values are denoted as mean \pm SE $(n=3)$. Values followed by different letters are significantly different $(p \leq 0.05)$ according to LSD test. Where treatments are Control (CK), Low Salt Stress (LS), and Medium Salt Stress (MS), while CT = no 1-MCP treatment and 1-MCP =1-MCP treatment. Liangyoupeijiu (LYP9) and Nipponbare (NPBA) are rice cultivars. $P$-values of the two-way ANOVAs of 1 -MCP, salt stress, and their interaction are indicated: ns, not significant; ${ }^{*} P<0.05 ;{ }^{* *} P<0.01 ;{ }^{* * *} P<0.001$. Bars with the same letter are not significantly different in the LSD test. 
may be due to the osmotic, ionic, and hormonal variations caused by salt stress. 1-MCP treatment performed better regulating results in LYP9 under adverse salt stress conditions. LYP9 showed susceptibility against the HS level, whereas NPBA could not survive at the HS level. These results suggested that NPBA is a highly sensitive rice cultivar.

\section{Grain Yield}

Salt stress commonly reduces rice grain yield as salt levels increase. During the 2016-2017 experiments, the average grain yield per plant for LYP9 decreased by $14.3 \%$ (LS) and $41.6 \%$ (MS), and $85.5 \%$ (HS), compared with that of CK. In the NPBA cultivar, with an increased salt level, rice grain yield reduced by 4.7 and $52.3 \%$ under LS and MS, compared with no salt stress (CK), respectively. The application of 1MCP increased the grain yield of both LYP9 and NPBA, with various salt levels (Figures 6A-D). In the LYP9, the mean value of rice grain yield was $19.4 \%$ (CK), $30.3 \%$ (LS), 26.4\% (MS), and 34.5\% (HS) higher with 1-MCP application than without 1-MCP application, compared to similar salt stress levels.
The rice grain yield per plant after application of 1MCP in NPBA was $15.1 \%$ (CK), 24\% (LS), and $55.4 \%$ (MS) higher than that without 1-MCP application. The rice seedlings died under heavy salt stress levels. Two-year results suggested that salt stress could adversely affect rice grain yield, while 1-MCP application could positively improve the yield.

\section{DISCUSSION}

High salt concentrations in soil enhanced the ethylene biosynthesis and affected the homeostasis of rice growth features and physiology (Sajid et al., 2018). The use of 1-MCP as an ethylene action inhibitor, to manage oxidative stress in rice plants, showed a close relationship to physiological, biochemical, antioxidants responses, and total above ground biomass, along with grain yield per plant to salt stress in rice. However, this is dependent on the level of ethylene receptors, the sites of the tissues, and synthesis. Salt stress might play an important role in the reaction to ethylene and will help us understand the effects

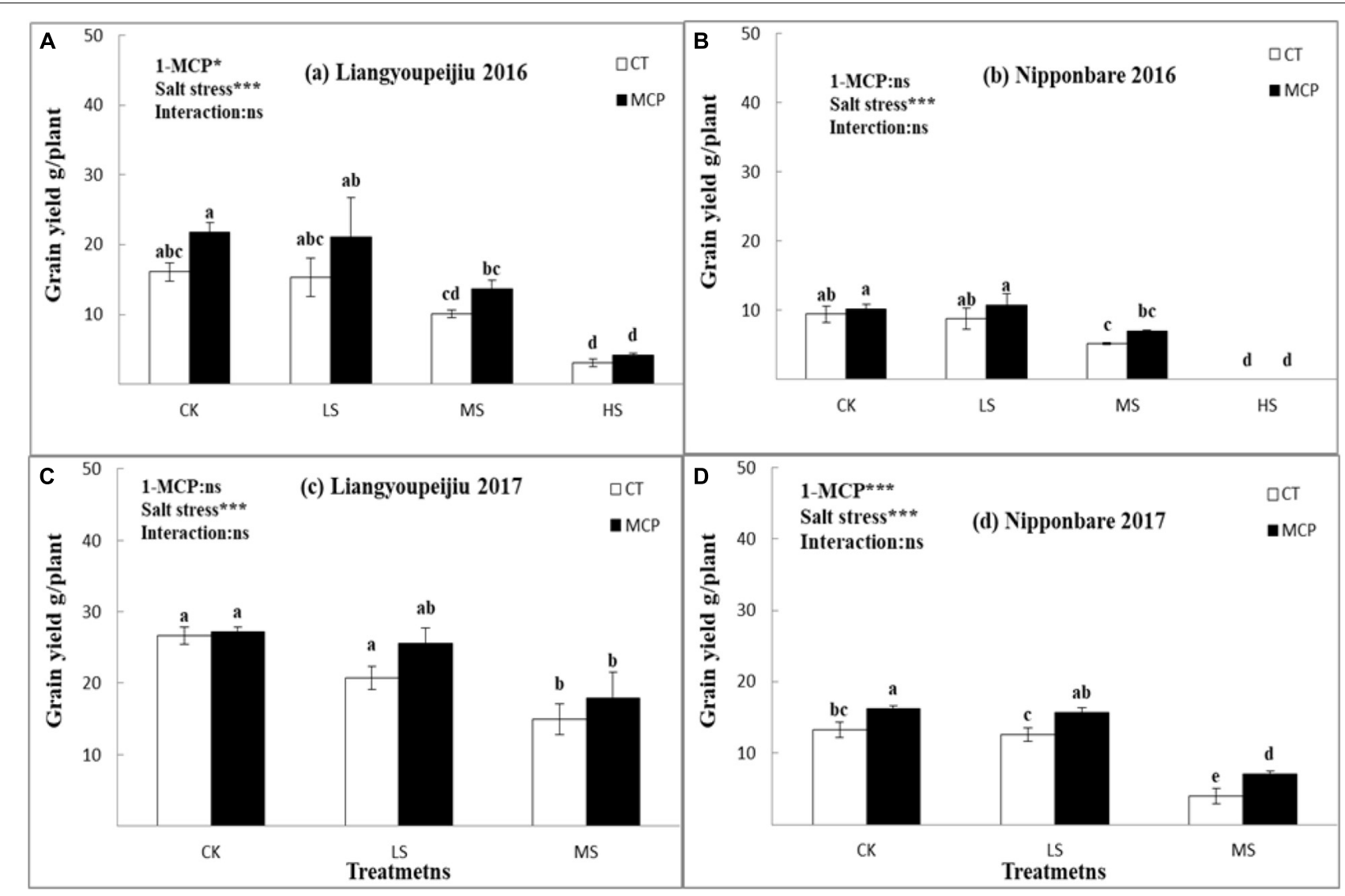

FIGURE 6 | Comparison effects of 1-MCP and salt levels on yield per plant (A-D) in 2016 and 2017. Values are denoted as mean \pm SE $(n=4)$. Values followed by different letters are significantly different $(p \leq 0.05)$ according to LSD test. Where treatments are Control (CK), Low Salt Stress (LS), and Medium Salt Stress (MS), while CT $=$ no 1-MCP treatment and 1-MCP $=1-\mathrm{MCP}$ treatment. Liangyoupeijiu (LYP9) and Nipponbare (NPBA) are rice cultivars. $P$-values of the two-way ANOVAs of 1-MCP, salt stress, and their interaction are indicated: ns, not significant; ${ }^{*} P<0.05 ;{ }^{* * *} P<0.001$. Bars with the same letter are not significantly different in the LSD test. 
of 1-MCP (Kevany et al., 2007). Many researchers also reported that receptor specification isoforms have special roles in specific physiological reactions to stress (Binder et al., 2006; Kevany et al., 2007). Increased salt stress imposed oxidative, osmotic, enzymatic, and hormonal imbalances on plant growth and might cause plant death (Cotsaftis et al., 2011), so a slight increase in salt levels in a plant cell resulted in adverse effects on the rice lifecycle. Salt stress affects numerous physiological, agronomical, and biochemical processes, i.e., superoxide dismutase (SOD), malondialdehyde (MDA), $\mathrm{H}_{2} \mathrm{O}_{2}$, proline, and chlorophyll contents, e.g., chl $a, b$, carotenoids. Moreover, it also affects soluble protein accumulation and growth characteristics such as aboveground biomass production and yield (Mostofa et al., 2015; Parihar et al., 2015). 1-MCP is a unique ethylene action inhibitor; 1-MCP has a low molecular weight and shows ten times more affinity to inhibit ethylene than other inhibitors because of its special $\alpha$-cyclodextrin ( $\alpha$-CD), and is environmentally friendly (In et al., 2013; Kawakami et al., 2010). Moreover, 1-MCP also contributes to rice plant growth regulating functions (Wang et al., 2012; Zhang et al., 2015).

The outcome of this 2-year experiment suggests that the exogenous usage of $1-\mathrm{MCP}$ results in encouraging effects on physiological and agronomic characteristics and shows significant effects on the homeostasis of biochemical characteristics, especially $\mathrm{SOD}, \mathrm{MDA}, \mathrm{H}_{2} \mathrm{O}_{2}$, proline, soluble proteins and chlorophyll contents. The less effective results of 1-MCP on NPBA than LYP9 may be because of the highly sensitive nature of NPBA. The LYP9 cultivar showed a high susceptibility against heavy salt stress levels (HS).

Salt stress negatively affected the physiological characteristics $\left(\mathrm{P}_{\mathrm{n}}\right.$ and SPAD values) of rice under increased salt concentrations. In this experiment, these parameters were reduced by salt stress in both LYP9 and NPBA. The application of 1-MCP significantly improved the $\mathrm{P}_{\mathrm{n}}$ and SPAD values under $C K$, LS, MS, and HS in LYP9. However, the NPBA plant died at the HS level. This might be due to the involvement of 1-MCP in improving the physiological and molecular mechanisms by the positive 1-Aminocyclopropane-1-carboxylic acid synthase (ACS), 1-aminocyclopropane-1-carboxylate oxidase (ACO), cell-wall-transforming enzymatic mechanisms, and the expression of GhCell in the abscission region of the plant leaf, which hinders the breaking of the tissue of leaves due to ethylene action inhibition (Mishra et al., 2008; Zhang et al., 2014). 1-MCP improves the photosystem II quantum efficiency, increases membrane integrity, and delays leaf senescence, ultimately enhancing the physiological characteristics of the plant (Loka and Derrick, 2013; Chen et al., 2015; shown in Figures 1A-H).

Ethylene is a stress plant hormone that when enhanced under unfavorable environments (salt stress), leads to leaf senescence and early maturity of fruits, finally causing yield reduction (Quinet et al., 2010; Loka and Derrick, 2013). From methionine the S-AdeMet (SAM), the primary ethylene precursor changes into 1-Aminocyclopropane-1-carboxylic acid (ACC) using 1Aminocyclopropane-1-carboxylic acid synthase (ACC synthase) and finally produces ethylene biosynthesis in response to the synthase oxidase (ACC oxidase) under a salt stress environment
Pandey et al., 2000; (Lin et al., 2009). 1-Aminocyclopropane-1carboxylic acid (ACC) has passive effects on ethylene production in the plant under stress conditions (Rudus et al., 2013; Zhang et al., 2014). High ethylene biosynthesis in rice spikelets is among the key grain yield-decreasing factors in salt-affected soil environments (Sajid et al., 2018). High ethylene production affects the physiology of the rice plant and passively disturbs assimilation of starch (Mohapatra and Panigrahi, 2011). It also affects the accumulation of starch contents in rice grains through the ethylene receptor ETR2 responsible monosaccharide transport gene (Wuriyanghan et al., 2009).

Therefore, in order to enhance rice grain yield, management approaches to ethylene action hang-ups are needed in amalgamation with improvements in genetic engineering under salt affected conditions (Yang et al., 2007). The use of an ethylene action binder improved the development of rice spikelets and plant dry biomass (Zhang et al., 2014, 2015; Sajid et al., 2018). Numerous studies revealed that ethylene inhibitors are a useful tool in coordinating the development of rice spikelets, especially inferior spikelets of japonica and indicia rice cultivars (Wang et al., 2012; Zhang et al., 2014, 2015; Sajid et al., 2018).

In this research experiment, the use of $1-\mathrm{MCP}$ as an ethylene action inhibitor meaningfully stopped the ethyleneinduced mechanism in spikelets under unfavorable salt affected environment levels such as CK, LS, MS, and HS in both LYP9 and NPBA rice cultivars (Figures 2A-D). This inhibition of ethylene action in rice spikelets is due to the unique behavior of 1-MCP as an ethylene action inhibitor. 1-MCP has an affinity to fix the ethylene receptors sites irretrievably. Consequently, signaling translation and transduction reactions are not motivated, and it chunks the protein synthesis and enzymatic action mechanisms through high ethylene production (Arigita et al., 2003; Su and Finlayson, 2012) and plants grow normally after this phenomenon.

Agronomic traits, i.e., aboveground biomass production (Figures 5A-D). This reduction is due to an osmotic, ionic, and hormonal imbalance especially in ethylene effects in rice plants, which vary in rice growth stages, as observed by Zeng and Shannon (2000); Shibli et al. (2007), Zhang et al. (2014), and Sajid et al. (2018). The decreased length of roots and shoots under abiotic stress ultimately decreased Pn mechanism, which resulted in less production of plant biomass (Amirjani, 2011; Sajid et al., 2018). Zhang et al. (2014) and Sajid et al. (2018) found similar results in the effects of $1-\mathrm{MCP}$ on growth parameters and the development of rice spikelets under normal field and salt stress conditions. Based on total above ground biomass production at the maturity stage, we can classify both cultivars, since LYP9 was susceptible to the HS levels, and NPBA was highly sensitive at the HS level.

Grain yield per plant reduced with increased salt stress levels (Figures 6A-D). The reduced grain yield per plant under salt stress levels was caused by the reduction of soluble sugar (starch) content transformation in rice spikelets and the starch synthetase activity decrease during grain development (Abdullah et al., 2001). These findings revealed that 1 -MCP plays a remarkable role in the regulation of the flag leaf functions by improving the Pn and SPAD value, resulting in an improvement in rice spikelets 
under salt stress. In the present study, 1-MCP increased the rice grain yield of LYP9 and NPBA cultivars under controlled and salt stress (Figures 6A-D).

Under salt stress conditions, membrane lipid peroxidation (MDA) is an indicator of cell membrane leakage and rupturing (Katsuhara et al., 2005). Malondialdehyde was increased in rice with increased salt stress levels. Hossain et al. (2013) and Kaur et al. (2016) reported a similar trend of increasing MDA contents in rice leaf tissues under salt stress. The steady escalation of MDA observed in this study is a clear indication that salt stress significantly affected oxidants and caused a rapid osmotic adjustment that released oxidative stress. This trend signifies that an increase in MDA is useful to protect plant mechanisms from salt stress in rice cultivars LYP9 and NPBA (Figures $4 \mathrm{E}-$ H). These results were also observed in other cereal crops such as wheat, and our outcomes are supported by Goudarzi and Pakniyat (2009); Srivashtav et al. (2015), and Kaur et al. (2016).

Proline proved to be an osmoprotectant as well as an osmoregulatory through osmotic effects due to abiotic stresses (salt stress) and enabled the plant to sustain development (Srivashtav et al., 2015). Higher proline synthesis in transgenic rice causes an improvement in salt tolerance (Srivashtav et al., 2015). Proline concentration plays a crucial role in protecting the cellular structures, especially the protein structure, against oxidative damage through scavenging the free radicals produced by abiotic stressors such as salt stress, chilling, and drought (Silva et al., 2013). Proline contents increased with increasing $\mathrm{NaCl}$ concentrations in plant leaf tissues. In this study, the increase in proline is useful to protect plant mechanisms against salt stress in rice cultivars LYP9 and NPBA, though the NPBA cultivar could not survive in high salt stress (Figures 3A-D). Ahmed et al. (2013) and Islam et al. (2015a) found the same results in rice and barley plants under salt and drought stress. Proline induced by salt stress might be an acclamatory response to improve salt tolerance in rice cultivars (Parihar et al., 2015). High proline in LYP9 under all salt stress levels showed its susceptibility to salt stress (Figures 3A-D).

In this study, the protein contents decreased with increasing $\mathrm{NaCl}$ concentration in plant leaf tissues of both rice cultivars LYP9 and NPBA (Figures 3E-H). Protein contents were higher in LYP9 than in NPBA under salt stress. This variation shows that a higher accumulation of protein in LYP9 flag leaves than in NPBA, protecting the cell from salt stress. Salt stress causes an imbalance in ions which involve in the synthesis of soluble protein and photosynthesis and cause degradation of chlorophyll contents (Di Martino et al., 2003). The reduction of protein contents in flag leaves might be due to an $\mathrm{Na}^{+}$and $\mathrm{K}^{+}$imbalance in plant tissues. Decreasing $\mathrm{K}^{+}$passively affects the protein synthesis and cause the destruction of plant growth features (Chen et al., 2007). 1MCP improved the protein contents in both rice cultivars under salt stress conditions (Figures 3E-H).

SOD (Superoxide Dismutase) is a key superoxide $\left(\mathrm{O}^{-2}\right)$ scavenger because of its enzymatic action. In this study, increased salt concentration decreased SOD contents in rice flag leaves. A similar study was done by Benitez et al. (2013). These results suggest that the reduction in SOD activity, due to salt stress, could be a major factor of significant membrane damage and increased MDA content under oxidative stress (Figures 4AD). The decrease in SOD activity in rice leaves follows the " $\mathrm{O}_{2}$ " accretion in leaf cells, and consequently, they block related enzymatic and non-enzymatic activities (Sarwar et al., 2003; Jajic et al., 2015). Similar results were found in cotton crops under stress when 1-MCP was used (Chen et al., 2015).

$\mathrm{H}_{2} \mathrm{O}_{2}$ is a basic element of oxidative metabolism. It is a product of peroxisomal and chloroplastic oxidative reactions, and it is an active oxygen species (Del Rio et al., 1992). The increase of ROS seems to occur as a response to abiotic stresses such as salt stress. $\mathrm{H}_{2} \mathrm{O}_{2}$ might perform a vital role in the salt injury mechanism (Singha and Choudhuri, 1999). $\mathrm{H}_{2} \mathrm{O}_{2}$ accumulation, caused by salinity, has been studied in many plants, e.g., Vigna catjang, rice, and pea plants (Hernandez et al., 1993). $\mathrm{H}_{2} \mathrm{O}_{2}$ was important in regulating salt injury in our rice leaf system. In this study, there was no significant effect under salt stress and 1MCP application. The activity of GO, the enzymes which catalyze the synthesis of $\mathrm{H}_{2} \mathrm{O}_{2}$ in the peroxisome, remained unchanged in control leaves. These results are very important for the homeostatic mechanism in ROS and antioxidants (Figures 4I,J).

Total chlorophyll contents (chlorophyll $a, b$, carotenoids) reduced in concentration, possibly due to the inhibition effect of the accumulation of various ions caused by salts stress, in the production of the various chlorophyll contents (Ali et al., 2004). In this study chlorophyll contents decreased with increased salt stress. Our results are supported by Adnan and Erkan (2016). This decrease in the Chlorophyll content in rice flag leaves might be because of the increase in variability pigments protein complexity and the activity of the Chls enzyme (Beinsan et al., 2009) Table 2.

The mitigating effects of the 1-MCP application on SOD, MDA, $\mathrm{H}_{2} \mathrm{O}_{2}$, proline, protein, and chlorophyll contents, i.e., chl $a, b$, and carotenoids, and total chlorophyll contents, in rice flag leaves under various salt levels, could be caused by its role in the rice plant as a signaling molecule. 1-MCP inhibits ethylene action and triggers plant defense responses and modulate homeostasis for cellular redox, including biochemical mechanisms, ion balance, and responses to oxidative stress (Sharma et al., 2012).

\section{CONCLUSION}

Salt stress significantly decreased agronomical, physiological, and biochemical characteristics of rice plants, as well as increased the ethylene production in spikelets. Application of 1-MCP resulted in favorable responses to salt stress, and 1-MCP proved to be an effective ethylene inhibitor. 1-MCP could not only significantly inhibited ethylene action in rice spikelets but, also improved physiological characteristics, such as $\mathrm{P}_{\mathrm{n}}$ and SPAD values under increased salt levels in both rice cultivars. 1-MCP also improved agronomical and biochemical characteristics such as SOD, soluble protein, chlorophyll content, and decreased MDA, $\mathrm{H}_{2} \mathrm{O}_{2}$ contents, and proline in flag leaves of rice. The homeostasis of these characteristics, due to 1-MCP application, resulted in improvements in aboveground biomass, and grain yield for rice plants under various salt stress levels. The usage of 
1-MCP proved to be one of the most important strategies for enhancing the rice plant's performance in response to salt stress. The results provided a strong base for the modulation of physiological, agronomical, and biochemical characteristics of rice under salt stress, through the use of 1-MCP. In future, our focus is to further study the effects of 1-MCP on genetic and molecular responses to salt stress in the rice plant.

\section{AUTHOR CONTRIBUTIONS}

$\mathrm{SH}, \mathrm{JZ}$, and QJ conceived and designed the study and conducted the experiments. $\mathrm{JH}, \mathrm{XC}, \mathrm{CZ}, \mathrm{ZB}$, and $\mathrm{LZ}$ contributed the

\section{REFERENCES}

Abdullah, Z., Khan, M. A., and Flowers, T. J. (2001). Causes of sterility in seed set of rice under salinity stress. J. Agron. Crop Sci. 187, 25-32. doi: 10.1046/j.1439037X.2001.00500.X

Adnan, A., and Erkan, Y. (2016). Effect of salinity stress on chlorophyll, carotenoid content, and proline in Salicornia prostrata Pall. And Suaeda prostrata Pall. subsp. prostrata (Amaranthaceae). Braz. J. Bot. 39, 101-106. doi: 10.1007/ s40415-015-0218-y

Agarwal, S. V., and Pandey, V. (2004). Antioxidant enzyme responses to $\mathrm{NaCl}$ stress in Cassia angustifoli. Biol. Plant 48, 555-560. doi: 10.1023/B:BIOP.0000047152. 07878.e7

Ahmed, I. M., Dai, H. X., Zheng, W., Cao, F. B., Zhang, G. P., Sun, D. F., et al. (2013). Genotypic differences in physiological characteristics in the tolerance to drought and salinity combined stress between Tibetan wild and cultivated barley. Plant Physiol. Biochem. 63, 49-60. doi: 10.1016/j.plaphy.2012.11.004

Ali, Y., Aslam, Z., Ashraf, M. Y., and Tahir, G. R. (2004). Effect of salinity on chlorophyll concentration, leaf area, yield and yield components of rice genotypes grown under saline environment. Int. J. Environ. Sci. Technol. 1, 221-225. doi: 10.1007/BF03325836

Amirjani, M. R. (2010). Effect of $\mathrm{NaCl}$ on some physiological parameters of rice. Eur. J. Biol. Sci. 3, 6-16.

Amirjani, M. R. (2011). Effect of salinity stress on growth, sugar content, pigments and enzyme activity of rice. Int. J. Bot. 7, 73-81. doi: 10.3923/ijb.2011.73.81

Arigita, L., Sanchez, R., and Gonzalez, A. (2003). 1-Methylcyclopropene and ethylene as regulators of in vitro organogenesis in kiwi explants. Plant Growth Regul. 40, 59-64. doi: 10.1023/A:1023070131422

Bates, L. S., Waldren, R. P., and Teare, D. (1973). Rapid determination of free proline for water-stress studies. Plant Soil 39, 205-207. doi: 10.1016/j.dental. 2010.07.006

Beinsan, C., Camen, D., Sumalan, R., and Babau, M. (2009). "Study concerning salt stress effect on leaf area dynamics and chlorophyll contain in four bean local landraces from Banat area," in Proceedings of the 44th Croatian and 4th International Symposium on Agriculture, Timi?oara.

Beltrano, J., Carbone, A., Montaldi, E. R., and Guiamet, J. J. (1994). Ethylene as a promoter of wheat grain maturation and ear senescence. Plant Growth Regul. 15, 107-112. doi: 10.1007/BF00024098

Benitez, L. C., Ribeiro, M. V., Deuner, S., da Maia, L. C., Peters, J. A., and Bolacel Braga, E. J. (2013). Alteration of biochemical and antioxidant mechanisms in rice plants under salt stress. Afr. J. Agric. Res. 8, 5923-5931.

Binder, B. M., O’Malley, R. C., Wang, W. Y., Zutz, T. C., and Bleecker, A. B. (2006). Ethylene stimulates mutations that are dependent on the ETR1 receptor. Plant Physiol. 142, 1690-1700. doi: 10.1104/pp.106.087858

Blankenship, S. M., and Dole, J. M. (2003). 1-Methylcyclopropene: a review. Postharv Biol. Tech. 28, 1-25. doi: 10.1016/S0925-5214(02)00246-6

Brennan, T., and Frenkel, C. (1977). Involvement of hydrogen peroxide in the regulation of senescence in pear. Plant Physiol. 59, 411-416. doi: 10.1104/pp. 59.3.411

Chen, Y., Cothren, J. T., Chen, D., Amir, M. H. I., and Leonardo, L. (2015). Ethylene-inhibiting compound 1-MCP delays leaf senescence in cotton plants analytical tools. SH and CZ analyzed the data. SH and JZ wrote the manuscript. MK revised the manuscript. The manuscript has been revised and approved by all authors.

\section{FUNDING}

This study was supported by the National Key Research and Development Program of China (2016YFD0200801), the Natural Science Foundation of China (31872857), the Key Research and Development Program of Zhejiang Province, China (2016C02050-3), and the Natural Science Foundation of Zhejiang Province, China (LY16C130007).

under abiotic stress conditions. J. Integr. Agric. 14, 1321-1331. doi: 10.1016/ S2095-3119(14)60999-0

Chen, Z., Cuin, T. A., Zhou, M., Twomey, A., Naidu, B. P., and Shabala, S. (2007). Sergey. Compatible solute accumulation and stress-mitigating effects in barley genotypes contrasting in their salt tolerance. J. Exp. Bot. 58, 4245-4255. doi: 10.1093/jxb/erm284

Cotsaftis, O., Pletta, D., Alexander, A. T. J., Harkamal, W., Clyde, W., Abdelbagi, M. I., et al. (2011). Root-specific transcript profiling of contrasting rice genotypes in response to salinity stress. Mol. Plant 4, 25-41. doi: 10.1093/mp/ ssq056

Del Rio, L. A., Sandalio, L. M., Corpas, F. J., Palma, J. M., and Barroso, J. B. (2006). Reactive oxygen species and reactive nitrogen species in peroxisomes. Production, scavenging, and role in cell signaling. Plant Physiol. 141, 330-335. doi: 10.1104/pp.106.078204

Del Rio, L. A., Sandalio, L. M., Palma, J. M., Bueno, P., and Corpus, F. J. (1992). Metabolism of oxygen radicals in peroxisomes and cellular implications. Free Rad. Biol. Med. 13, 557-580. doi: 10.1016/0891-5849(92)90150-F

Di Martino, C., Sebastiano, D., Pizzuto, R., Loreto, F., and Fuggi, A. (2003). Free amino acid and glycine betaine in leaf osmoregulation of spinach responding to increasing salt stress. New Phytol. 158, 455-463. doi: 10.1046/j.1469-8137.2003. 00770.x

Esfahani, M., Abbasi, H. R. A., Rabiei, B., and Kavousi, M. (2008). Improvement of nitrogen management in rice paddy fields using chlorophyll meter (SPAD). Paddy Water Environ. 6, 181-188. doi: 10.1007/s10333-007-0094-6

Giannopolitis, C. N., and Ries, S. K. (1977). Superoxide dismutases, occurrence in higher plants". Plant Physiol. 59, 309-314. doi: 10.1104/pp.59.2.309

Goudarzi, M., and Pakniyat, H. (2009). Salinity causes increase in proline and protein contents and peroxidase activity in wheat cultivars. J. Appl. Sci. 9, 348-353. doi: 10.3923/jas.2009.348.353

Hairmansis, A., Nafisah, N., and Jamil, A. (2017). Towards developing salinity tolerant rice adaptable for coastal regions in Indonesia. KnE Life Sci. 2, 72-79. doi: $10.18502 / \mathrm{kls}$.v2i6.1021

Harper, G. (2015). 1-Methylcyclopropene: a review of its use on potato tubers. Agric. Hortic. Dev. Board 1-16.

Hernandez, J. A., Corpas, F. J., Gomez, M., del Rio, L. A., and Secilla, F. (1993). Salt-induced oxidative stress mediated by activated oxygen species in pea leaf mitochondria. Physiol. Plant 89, 103-110. doi: 10.1111/j.1399-3054.1993. tb01792.x

Hossain, M. A., Ismail, M. R., Uddin, M. K., Islam, M. Z., and Ashrafuzzaman, M. (2013). Efficacy of ascorbate-glutathione cycle for scavenging $\mathrm{H} 2 \mathrm{O} 2$ in two contrasting rice genotypes during salinity stress. Aust. J. Crop Sci. 7, 1801-1808.

In, B. C., Strable, J., Binder, B. M., and Falbel, T. G. (2013). Patterson, S. E., morphological and molecular characterization of ethylene binding incarnations. Post Harvest Biol. Technol. 86, 272-279. doi: 10.1016/j. postharvbio.2013.07.007

Iqbal, N., Shahid, U., and Khan, N. A. (2015). Nitrogen availability regulates proline and ethylene production and alleviates salinity stress in mustard (Brassica juncea). J. Plant Physiol. 178, 84-91. doi: 10.1016/j.jplph.2015.02.006

Islam, F., Ali, S., Farooq, M. A., Wang, J., Gill, R. A., Zhu, J., et al. (2017a). Butachlor-induced alterations in ultrastructure, antioxidant, and 
stress-responsive gene regulations in rice cultivars. CLEAN Soil Air Water 45:1500851. doi: 10.1002/clen.201500851

Islam, F., Farooq, M. A., Gill, R. A., Wang, J., Yang, C., Ali, B., et al. (2017b). 2,4-D attenuates salinity-induced toxicity by mediating anatomical changes, antioxidant capacity and cation transporters in the roots of rice cultivars. Sci. Rep. 7:10443. doi: 10.1038/s41598-017-09708-x

Islam, F., Yasmeen, T., Arif, M. S., Ali, S., Ali, B., Hameed, S., et al. (2015a). Plant growth promoting bacteria confer salt tolerance in vignaradiata by upregulating antioxidant defense and biological soil fertility. Plant Growth Regul. 1, 1-14.

Jajic, I., Sarna, T., and Strzalka, K. (2015). Senescence, stress, and reactive oxygen species. Plants 4, 393-411. doi: 10.3390/plants40 30393

Katsuhara, M., Otsuka, T., and Ezaki, B. (2005). Salt stress-induced lipid peroxidation is reduced by glutathione S-transferase, but this reduction of lipid peroxides is not enough for a recovery of root growth in Arabidopsis. Plant Sci. 169, 369-373. doi: 10.1016/j.plantsci.2005.03.030

Kaur, N., Dhawan, M., Sharma, I., and Kumar, P. P. (2016). Interdependency of reactive oxygen species generating and scavenging system in salt sensitive and salt tolerant cultivars of rice. BMC Plant Biol. 16:131. doi: 10.1186/s12870-0160824-2

Kawakami, E. M., Oosterhuis, D. M., and Snider, J. L. (2010). Physiological effects of 1-methylcyclopropene on well-watered and water-stressed cotton plants. J. Plant Growth Regul. 29, 280-288. doi: 10.1007/s00344-009-9134-3

Kevany, B. M., Tieman, D. M., Taylor, M. G., Cin, V. D., and Klee, H. J. (2007). Ethylene receptor degradation controls the timing of ripening in tomato fruit. Plant J. 51, 458-467. doi: 10.1111/j.1365-313X.2007.03170.x

Kromdijk, J., and Long, S. P. (2016). One crop breeding cycle from starvation? How engineering crop photosynthesis for rising $\mathrm{CO} 2$ and temperature could be one important route to alleviation. Proc. Biol. Sci. 283:20152578. doi: 10.1098/rspb. 2015.2578

Li, X. J., Han, B., Xu, X. Y., Han, L. P., Zhao, Y. Y., Liu, Z. L., et al. (2014). Plant growth enhancement and associated physiological responses are co-regulated by ethylene and gibberellin in response to harpin protein. Hpa1. Planta 239, 831-846. doi: 10.1098/rspb.2015.2578

Lin, Z., Zhong, S., and Grierson, D. (2009). Recent advances in ethylene research. J. Exp. Bot. 60, 3311-3336. doi: 10.1007/s00425-013-2013-y

Loka, D. A., and Derrick, M. O. (2013). Effect of 1-MCP on gas exchange and carbohydrate concentrations of the cotton flower and subtending leaf under water-deficit stress. Am. J. Plant Sci. 4, 142-152. doi: 10.1093/jxb/erp204

Mantri, N., Patade, V., Penna, S., Ford, R., and Pang, E. (2012). “Abiotic stress responses in plants: Present and future," in Abiotic Stress Responses in Plants: Metabolism, Productivity, and Sustainability, eds P. Ahmad and M. N. V. Prasad (New York, NY: Springer), 1-19. doi: 10.4236/ajps.2013.41019

Miller, G., Suzuki, N., Ciftci-Yilmaz, S., and Mittler, R. (2010). Reactive oxygen species homeostasis and signaling during drought and salinity stresses. Plant Cell Environ. 33, 453-467. doi: 10.1111/j.1365-3040.2009.02041.x

Mishra, A., Khare, S., Trivedi, P. K., and Nath, P. (2008). Effect of ethylene, 1-MCP, $\mathrm{ABA}$ and IAA on break strength, cellulose and polygalacturonase activities during cotton leaf abscission. S. Afr. J. Bot. 74, 282-287. doi: 10.1016/j.sajb.2007. 12.001

Mohapatra, P. K., and Panigrahi, R. (2011). "Ethylene control of grain development in the inferior spikelets of rice panicle," in Advances in Plant Physiology, Vol. 12, ed. A. Hemantaranjan (Jodhpur: Scientific Publishers), 79-89.

Mostofa, G. M., Saegusa, D., Fujita, M., and Phan, T. L. (2015). Hydrogen sulfide regulates salt tolerance in rice by maintaining $\mathrm{Na}+/ \mathrm{K}+$ balance, mineral homeostasis, and oxidative metabolism under excessive salt stress. Front. Plant Sci. 6:1055. doi: 10.3389/fpls.2015.01055

Munns, R. (2011). Plant Adaptations to Salt and Water Stress: Differences and Commonalities, Advances in Botanical Research, Vol. 57. Cambridge: Academic Press, 1-32. doi: 10.1016/B978-0-12-387692-8.00001-1

Mustafiz, A., Singh, A. K., Pareek, A., Sopory, S. K., and Singla-Pareek, S. L. (2011). Genome-wide analysis of rice and Arabidopsis identifies two glyoxalase genes that are highly expressed in abiotic stress. Funct. Integr. Genomics 11, 293-305. doi: 10.1007/s10142-010-0203-2

Navrot, N., Rouhier, N., Gelhaye, E., and Jaquot, J. P. (2007). Reactive oxygen species generation and antioxidant systems in plant mitochondria. Physiol. Plant 129, 185-195. doi: 10.1111/j.1399-3054.2006.00777.x
Nellemann, C., Devette, M. M., and Manders, T. (2009). The Environmental Food Crisis - The Environment's Role in Averting Future Food Crises. Nairobi: United Nations Environment Programme of the United Nations.

Pandey, S., Ranade, S. A., Nagar, P. K., and Kumar, N. (2000). Role of polyamines and ethylene as modulators of plant senescence. J. Biosci. 25, 291-299. doi: 10.1007/BF02703938

Pareek, A., Sopory, S. K., Bohnert, H. J., and Govindjee. (2010). Abiotic Stress Adaptation in Plants: Physiological, Molecular and Genomic Foundation. Berlin: Springer. doi: 10.1007/978-90-481-3112-9

Parida, A. K., and Das, A. B. (2005). Salt tolerance and salinity effects on plants: a review. Ecotoxicol. Environ. Saf. 60, 324-349. doi: 10.1016/j.ecoenv.2004. 06.010

Parihar, P., Singh, S., Singh, R., Singh, V. P., and Prasad, S. M. (2015). Effect of salinity stress on plants and its tolerance strategies: a review. Environ. Sci. Pollut. Res. 22, 4056-4075. doi: 10.1007/s11356-014-3739-1

Quinet, M., Ndayiragije, A., Lefevre, I., Lambillotte, B., Dupont, G. C. C., and Lutts, S. (2010). Putrescine differently influences the effect of salt stress on polyamine metabolism and ethylene synthesis in rice cultivars differing in salt resistance. J. Exp. Bot. 61, 2719-2733. doi: 10.1093/jxb/erq118

Rabbani, G., Rahman, A., and Mainuddin, K. (2013). Salinity-induced loss and damage to farming households in coastal Bangladesh. Int. J. Glob. Warm. 5, 400-415. doi: 10.1504/IJGW.2013.057284

Rajendran, K., Tester, M., and Roy, S. J. (2009). Quantifying the three main components of salinity tolerance in cereals. Plant Cell Environ. 32, 237-249. doi: 10.1111/j.1365-3040.2008.01916.x

Reddy, P. S., Jogeswar, G., Rasineni, G. K., Maheswari, M., Reddy, A. R., Varshney, R. K., et al. (2015). Proline over-accumulation alleviates salt stress and protects photosynthetic and antioxidant enzyme activities in transgenic sorghum [Sorghum bicolor (L.) Moench]. Plant Physiol. Biochem. 94, 104-113. doi: 10.1016/j.plaphy.2015.05.014

Roy, S. J., Negrao, S., and Tester, M. (2014). Salt resistant crop plants. Curr. Opin. Biotechnol. 26, 115-124. doi: 10.1016/j.copbio.2013.12.004

Ruan, C. J., da Silva, J. A. T., Mopper, S., Qin, P., and Lutts, S. (2010). Halophyte improvement for a salinized world. Crit. Rev. Plant Sci. 29, 329-359. doi: 10. 1080/07352689.2010.524517

Rudus, I., Sasiak, M., and Kepczy nski, J. (2013). Regulation of ethylene biocynthesis at the level of 1-aminocyclopropane-1carboxylate oxidase (ACO) gene. Acta Physiol. Plant. 35, 295-307. doi: 10.1007/s11738-012-1096-6

Sajid, H., Chu, Z., Zhigang, B., Xiaochuang, C., Lianfeng, Z., Azhar, H., et al. (2018). Effects of 1-Methylcyclopropene on rice growth characteristics and superior and inferior spikelet development under salt stress. J. Plant Growth Regul. 37, 1368-1384. doi: 10.1007/s00344-018-9800-4

Sarwar, G., Ashraf, M. Y., and Naeem, M. (2003). Genetic variability of some primitive bread wheat varieties to salt tolerance. Pakistan J. Bot. 35, 771-777.

Scopes, R. (1987). Protein Purification: Principles and Practice, 3rd Edn. New York, NY: Springer-Verlag, Inc. doi: 10.1007/978-1-4757-1957-4

Sedmak, J. J., and Grossberg, S. E. (1977). A rapid, sensitive and versatile assay for protein using Coomassie brilliant blue G 250. Anal. Biochem. 79, 544-552. doi: 10.1016/0003-2697(77)90428-6

Shao, H. B., Chu, L. Y., Lu, Z. H., and Kang, C. M. (2007). Primary antioxidant free radical scavenging and redox signaling pathways in higher plant cells. Int. J. Biol. Sci. 7, 8-14.

Sharma, P., Ambuj, B. J., Rama, S. D., and Mohammad, P. (2012). Reactive oxygen species, oxidative damage, and antioxidative defense mechanism in plants under stressful conditions review article. J. Bot. 2012, 1-26. doi: 10.1155/2012/ 217037

Shibli, R. A., Kushad, M., Yousef, G. G., and Lila, M. A. (2007). Physiological and biochemical responses of tomato microshoots to induced salinity stress with associated ethylene accumulation. Plant Growth Regul. 51, 159-169. doi: 10.1007/s10725-006-9158-7

Silva, E. N., Vieira, S. A., Ribeiro, R. V., Ponte, L. F., Ferreira-Silva, S. L., and Silveira, J. A. (2013). Contrasting physiological responses of Jatropha curcas plants to single and combined stresses of salinity and heat. J. Plant Growth Regul. 32, 159-169. doi: 10.1007/s00344-012-9287-3

Singha, S., and Choudhuri, M. A. (1999). Effect of salinity $(\mathrm{NaCl})$ stress on $\mathrm{H} 2 \mathrm{O} 2$ metabolism in Vigna and Oryza seedlings. Biochem. Physiol. Pflanz. 186, 69-74. doi: 10.1016/S0015-3796(11)80295-7 
Srivashtav, V., Rajkumar, J. H. A. S., and Singh, D. (2015). Effect of $\mathrm{NaCl}$ induced salt stress on proline, MDA and antioxidant mechanism in rice (Oryza Sativa L.). J. Cell Tissue Res. 15, 5037-5041.

Su, H. W., and Finlayson, S. (2012). 1-Methylcyclopropene prevents cotton physiological and molecular responses to ethylene. Plant Growth Regul. 68, 57-66. doi: 10.1007/s10725-012-9693-3

Tao, J. J., Chen, H. W., Ma, B., Zhang, W. K., Chen, S. Y., and Zhang, J. S. (2015). The role of ethylene in plants under salinity stress. Front. Plant Sci. 6:1059 doi: 10.3389/fpls.2015.01059

Trotta, F., Cavalli, R., Martina, K., Biasizzo, M., Vitillo, J., Borddiga, S., et al. (2011). Cyclodextrin nanosponges as effective gas carriers. J. Incl. Phenom. Macrocycl. Chem. 71, 189-194. doi: 10.1007/s10847-011-9926-5

Velikova, V., Yordanov, I., and Edreva, A. (2000). Oxidative stress and some antioxidant systems in the acid rain-treated bean plants protective role of exogenous polyamines. Plant Sci. 151, 59-66. doi: 10.1016/S0168-9452(99) 00197-1

Wang, Z. Q., Xu, Y. J., Wang, J. C., Yang, J. C., and Zhang, J. H. (2012). Polyamine and ethylene interactions in grain filling of superior and inferior spikelets of rice. Plant Growth Regul. 66, 215-228. doi: 10.1007/s10725-011-9644-4

Wellburn, A. R., and Lichtenthaler, H. K. (1984). "Formulae and program to determine total carotenoids and chlorophylls a and b of leaf extracts in different solvents," in Advances in Photosynthesis Research, ed. C. Sybesma (Dordrecht: Springer), 9-12. doi: 10.1007/978-94-017-6368-4_3

Wuriyanghan, H., Zhang, B., Cao, W., Ma, B., Lei, G., Liu, Y., et al. (2009). The ethylene receptor ETR2 delays floral transition and affects starch accumulation in rice. Plant Cell 21, 1473-1494. doi: 10.1105/tpc.108.065391

Yang, J. C., Zhang, J. H., Liu, K., Wang, Z. Q., and Liu, L. J. (2007). Abscisic acid and ethylene interact in rice spikelets in response to water stress during meiosis. J. Plant Growth Regul. 26, 318-328. doi: 10.1007/s00344-007-9013-8

Yang, W. B., Yin, Y. P., Li, Y., Cai, T., Ni, Y. L., Peng, D. L., et al. (2014). Interactions between polyamines and ethylene during grain filling in wheat grown under water deficit conditions. Plant Growth Regul. 72, 189-201. doi: 10.1007/s10725013-9851-2

Zeng, L., and Shannon, M. C. (2000). Salinity effects on seedling growth and yield components of rice. Crop Sci. 40, 996-1003. doi: 10.2135/cropsci2000.404996x

Zhang, H., Li, D., Zhou, Z., Zahoor, R., Chen, B., and Meng, Y. (2017). Soil water and salt affect cotton (Gossypium hirsutum L.) photosynthesis, yield and fiber quality in coastal saline soil. Agric. Water Manage. 187, 112-121. doi: 10.1016/j. agwat.2017.03.019

Zhang, H., Tan, G. L., and Wang, Z. Q. (2009). Ethylene and ACC levels in developing grains are related to the poor appearance and milling quality of rice. Plant Growth Regul. 58, 85-96. doi: 10.1007/s10725-0089354-8

Zhang, J. H., Lin, Y., Zhu, L. F., Yu, S. M., Kundu, S. K., and Jin, Q. Y. (2015). Effects of 1-methylcyclopropene on the function of flag leaf and development of superior and inferior spikelets in rice cultivars differing in panicle types. Field Crops Res. 177, 64-74. doi: 10.1016/j.fcr.2015.03.003

Zhang, J. H., Zhu, L. F., Yu, S. M., and Jin, Q. Y. (2014). Involvement of 1methylcyclopropene in plant growth, ethylene production, and synthase activity of inferior spikelets in hybrid rice differing in panicle architectures. J. Plant Growth Regul. 33, 551-561. doi: 10.1007/s00344-013-9404-y

Zhao, X. C., and Schaller, G. E. (2004). Effect of salt and osmotic stress upon expression of the ethylene receptor ETR1 in Arabidopsis thaliana. FEBS Lett. 562, 189-192. doi: 10.1016/S0014-5793(04)00238-8

Zhong, C., Cao, X., Hu, J., Zhu, L., Zhang, J., Huang, J., et al. (2017). Nitrogen metabolism in adaptation of photosynthesis to water stress in rice grown under different nitrogen levels. Front. Plant Sci. 8:1079. doi: 10.3389/fpls.2017. 01079

Zhu, G., Ye, N., Yang, J., Pend, X., and Zhang, J. (2011). Regulation of expression of starch synthesis genes by ethylene and ABA in relation to the development of rice inferior and superior spikelets. J. Exp. Bot. 62, 3907-3916. doi: 10.1093/ jxb/err088

Conflict of Interest Statement: The authors declare that the research was conducted in the absence of any commercial or financial relationships that could be construed as a potential conflict of interest.

Copyright (c) 2019 Hussain, Bai, Huang, Cao, Zhu, Zhu, Khaskheli, Zhong, Jin and Zhang. This is an open-access article distributed under the terms of the Creative Commons Attribution License (CC BY). The use, distribution or reproduction in other forums is permitted, provided the original author(s) and the copyright owner(s) are credited and that the original publication in this journal is cited, in accordance with accepted academic practice. No use, distribution or reproduction is permitted which does not comply with these terms. 